\title{
Impact of Titanium Dioxide Surface Defects on the Interfacial Composition and Energetics of Evaporated Perovskite Active Layers
}

\author{
R. Clayton Shallcross, ${ }^{*}$ a Selina Olthof, ${ }^{b}$ Klaus Meerholz, ${ }^{b}$ and Neal R. Armstrong ${ }^{a}$ \\ a Department of Chemistry and Biochemistry, University of Arizona, Tucson, AZ 85721, United States of America. \\ b Department of Chemistry, University of Cologne, Luxemburger Str. 116, 50939, Cologne, Germany. \\ ${ }^{*}$ Corresponding Author: R. Clayton Shallcross, E-mail: clayshal@email.arizona.edu
}

I. Experimental Section (pg. S-2 and S-3)

II. SI Figures:

Table S1. Estimated thickness/coverage of aminosilane layer for as-deposited APTES (APTES-AD), APTES-HCI and APTES-KOH samples (pg. S-4)

Figure S1. AR-XPS analysis of $\mathrm{TiO}_{2}$, APTES-AD, APTES-HCl and APTES-KOH samples (pg. S-5)

Figure S2. AR-XPS atomic ratios for $\mathrm{TiO}_{2}$, APTES-AD, APTES-HCl and APTES-KOH samples (pg. S-6)

Figure S3. MS analysis of gas-phase MAI species during co-evaporation of $\mathrm{MAl}$ and $\mathrm{Pbl}_{2}$ from quartz Knudsen cells (pg. S-7)

Figure S4. Attenuation of Ti $2 p$ and $\mathrm{O} 1 \mathrm{~s}$ XPS CL spectra during PAL film growth (pg. S-8)

Figure S5. XPS CL spectra of co-evaporated $\mathrm{MAI} / \mathrm{Pbl}_{2}$ films during film growth on $\mathrm{TiO}_{2}, \mathrm{APTES}-\mathrm{HCl}$ and $\mathrm{APTES}-$ $\mathrm{KOH}$ substrates (pg. S-9)

Figure S6. XRD analysis of solution-processed $\mathrm{MAPbl}_{3}$ and $\mathrm{MABr}$-doped (15 mol\% w.r.t. $\left.\mathrm{FAI}\right) \mathrm{FAPbl}_{3} \mathrm{PALs}$ on $\mathrm{TiO}_{2}$, APTES-HCl and APTES-KOH substrates (pg. S-10)

Figure S7. XPS CL BEs during MAl/Pbl ${ }_{2}$ film growth on $\mathrm{TiO}_{2}, \mathrm{APTES}-\mathrm{HCl}$ and $\mathrm{APTES}-\mathrm{KOH}$ contacts (pg. S11)

Figure S8. Monochromatic UPS SECO and VB spectra of as-deposited $\mathrm{TiO}_{2}\left(\mathrm{AD}-\mathrm{TiO}_{2}\right)$, oxygen plasma treated $\mathrm{TiO}_{2}$ $\left(\mathrm{TiO}_{2}\right)$, APTES- $\mathrm{HCl}$ and APTES-KOH samples (pg. S-12)

Figure S9. Energy diagram showing the evolution and equilibration of the buried $\mathrm{TiO}_{2}, \mathrm{APTES}-\mathrm{HCl}$ and $\mathrm{APTES}-\mathrm{KOH}$ interface energetics during co-evaporation of $\mathrm{MAl} / \mathrm{Pbl}_{2}$ films (pg. S-13)

Figure S10. Expanded view of UPS emission features associated with gap/defect states below the $\mathrm{TiO}_{2}$ and $\mathrm{PAL} V \mathrm{~B}$ edge during film growth. (pg. S-14)

Figure S11. Monochromatic UPS SECO and VB spectra of $\mathrm{MAl} / \mathrm{Pbl}_{2}$ films during growth on $\mathrm{TiO}_{2}, \mathrm{APTES}-\mathrm{HCl}$ and APTES-KOH substrates (pg. S-15)

Figure S12. Evidence of $\mathrm{Pb}^{0}$ during film growth (pg. S-16)

Figure S13. Correlation between $\mathrm{E}_{\mathrm{VBM}}$ and $\mathrm{N}(\mathrm{MA})$ content indicates that the MA concentration gradient is responsible for band bending in PALs on APTES-HCl and APTES-KOH samples (pg. S-17)

III. SI References (pg. S-18) 


\section{Experimental Section:}

Materials. Acetone (ACS grade, Fisher Chemical), ethanol (absolute, Decon Labs), toluene (ACS Grade, EMD), isopropanol (IPA, ACS Grade, EMD), titanium(IV) isopropoxide (TTIP, 97\%, Sigma Aldrich), (3aminopropyl)triethoxysilane (APTES, 99\%, Acros Organics Sure Seal), KOH (ACS Grade, BDH/VWR), HCl (ACS Grade, EMD), nanopure $\mathrm{H}_{2} \mathrm{O}\left(18.2 \mathrm{M} \Omega \cdot \mathrm{cm}\right.$ using a Milli-Q UV Plus Millipore water purification system) and $\mathrm{Pbl}_{2}$ (ultradry, 99.999\% metals basis, Alfa Aesar). N,N-dimethylformamide (DMF, anhydrous, 99.8\%, Sigma Aldrich), dimethylsulfoxide (DMSO, 99+\%, Alfa Aesar) and IPA used for solution-processed PALs have been dried over molecular sieves ( $3 \AA, 20 \% \mathrm{~m} / \mathrm{v}, 1$ week) and stored over fresh molecular sieves (i.e., sequentially dried to afford ultradry solvents). ${ }^{1}$ Methylammonium iodide (MAl), formamidinium iodide (FAl) and methylammonium bromide ( $\mathrm{MABr}$ ) have been prepared according to the literature. ${ }^{2}$

Preparation of ITO Substrates. ITO (Colorado Concept Coatings, LLC; ca. 10-15 $\Omega / s q$.$) is cut into 1" \times 1$ " pieces and cleaned by sonicating in a heated (ca. $70^{\circ} \mathrm{C}$ ) bath for 15 min each in Triton X-100 $\left(10 \% \mathrm{v} / \mathrm{v}\right.$ in nanopure $\left.\mathrm{H}_{2} \mathrm{O}\right), \mathrm{DI} \mathrm{H}_{2} \mathrm{O}$, acetone and IPA. The ITO substrates are rinsed with fresh IPA, dried with a stream of $\mathrm{N}_{2}$ and activated with oxygen plasma (Harrick PDC-3XG, Harrick Scientific) for $10 \mathrm{~min}$ ( $17 \mathrm{~W}$, ca. $800 \mathrm{mTorr}_{2}$ ) prior to $\mathrm{TiO}_{2}$ deposition.

$\underline{\text { CVD TiO }} 2$. Amorphous and conformal $\mathrm{TiO}_{2}$ films are deposited on activated ITO substrates in a home-built CVD system that has been described in previous publications..$^{2-3}$ Briefly, $4-1$ " $\times 1$ " ITO substrates are fixed on a heating stage and pumped down in a home-built CVD chamber to a base pressure of ca. 1 Torr. During a typical 25 min CVD run, titanium(IV) isopropoxide is delivered to heated $\left(210^{\circ} \mathrm{C}\right)$ ITO substrates in an ultra-high purity $\mathrm{N}_{2}$ carrier gas at a flow rate of $0.66 \mathrm{~cm}^{3} / \mathrm{min}$, providing for a working pressure and thickness of 1.35 Torr and ca. $30 \mathrm{~nm}$, respectively. After deposition, the CVD- $\mathrm{TiO}_{2}$ films are cooled and stored in dark, ambient conditions.

Vapor-Phase Deposition of APTES SAMs. The CVD-TiO films are partitioned into $4-1 / 2$ " $\times 1 / 2$ " pieces and treated using the aforementioned $\mathrm{O}_{2}$ plasma (OP) procedure for 10 min before bringing into a $\mathrm{N}_{2}$ glovebox $\left(<0.1 \mathrm{ppm} \mathrm{H}_{2} \mathrm{O}\right.$ and $<1$ $\mathrm{ppm} \mathrm{O}_{2}$ ). All glassware is dried overnight at $120^{\circ} \mathrm{C}$ in an air oven prior to bringing into the glovebox and allowing to cool to RT for silanization procedures. $4-1 / 2$ " $\times 1 / 2$ " pieces are equally spaced at the bottom of a glass jar (Qorpak, 60 $\mathrm{mL}$ ) with PTFE-wrapped threads. APTES $(30 \mu \mathrm{L})$ is added to a small glass crucible, which is placed in the center of the jar. The lid (green with a PTFE liner) is carefully fixed to the jar before placing onto a hot plate set to $85^{\circ} \mathrm{C}$ for 1 hour. The APTES-treated substrates are removed from the jar while still on the hot plate, placed on a petri dish that is equilibrated to the $85^{\circ} \mathrm{C}$ hot plate temperature and annealed for $10 \mathrm{~min}$. During this $85^{\circ} \mathrm{C}$ anneal, the $\mathrm{N}_{2}$ box is purged after the jar, lid and APTES-filled crucible are removed from the box. After cooling to RT, the APTES-treated $\mathrm{TiO}_{2}$ substrates are removed from the glovebox and rinsed with toluene and ethanol before being dried with a stream of $\mathrm{N}_{2}$ gas. The air-exposed and solvent-rinsed APTES-treated $\mathrm{TiO}_{2}$ substrates are brought back into the $\mathrm{N}_{2}$ glovebox and annealed on a hot plate at $120^{\circ} \mathrm{C}$ for $10 \mathrm{~min}$, yielding the as-deposited APTES sample (APTES-AD). Prior to loading the samples into ultra-high vacuum (UHV), APTES-AD samples are dipped into freshly-prepared aqueous $\mathrm{HCl}(50 \mathrm{mM}$, $\mathrm{pH}=1.3$ - "APTES-HCl") or $\mathrm{KOH}(2 \mathrm{mM}, \mathrm{pH}=11.3-$ "APTES-KOH") solutions for $15 \mathrm{~s}$ and thoroughly dried with a stream of $\mathrm{N}_{2}$.

Monochromatic AR-XPS Measurements of Pristine Surfaces. $\mathrm{TiO}_{2}$, APTES-AD, APTES-HCl and APTES-KOH samples are mounted in air and loaded into a Kratos Axis Ultra PES system with a base pressure of ca. $2 \times 10^{-9}$ Torr. AR-XPS core level (CL) spectra are acquired with a monochromatic Al Ka source (1486.6 eV, $20 \mathrm{~mA}, 15 \mathrm{kV}, 20 \mathrm{eV}$ pass energy) at a take-off angle (TOA) of $0^{\circ}$ and $60^{\circ}$ w.r.t. the surface normal. Average and standard deviation values for BEs and atomic ratios are determined by measuring at least three spots per sample $(n \geq 3)$. The XPS binding energy scale is calibrated with sputter-cleaned $\mathrm{Cu}\left(3 \mathrm{p}_{3 / 2}=75.10 \mathrm{eV} ; 2 \mathrm{p}_{3 / 2}=932.60 \mathrm{eV}\right)$, Au $\left(4 \mathrm{f}_{7 / 2}=84.00 \mathrm{eV}\right)$, and Ag $\left(3 \mathrm{~d}_{5 / 2}, 368.20 \mathrm{eV}\right)$ foils. XPS spectra are processed using the Vision 2 software package (Kratos Analytical). Relative atomic concentrations are quantified from background-corrected and systematically deconvoluted $\mathrm{CL}$ spectra, which are corrected for the orbital cross sections and KE-dependent analyzer transfer function.

XPS and Monochromatic UPS of Pristine Surfaces and Co-evaporated $\mathrm{MAl}_{\mathrm{Pb}} \mathrm{I}_{2}$ films. $\mathrm{TiO}_{2}, \mathrm{APTES}-\mathrm{HCl}$ and APTES$\mathrm{KOH}$ samples are loaded into the UHV chamber from ambient and transferred through the preparation chamber to the analysis chamber fo. The pristine contacts are analyzed in the PES analysis chamber (ca. $8 \times 10^{-10} \mathrm{mbar}$ ) prior to transfer to the ., CL spectra are taken using a non-monochromatic Mg Ka XPS source (1253.6 eV, $20 \mathrm{~mA}, 12 \mathrm{kV}$ ) at a takeoff angle of $0^{\circ}$ and a Phoibos 100 hemispherical analyzer ( $10 \mathrm{eV}$ pass energy). Due to time limitations and the total number of XPS measurements per sample and nominal thickness, statistics are not provided for the reported BEs and atomic ratios during growth of co-evaporated $\mathrm{MAl} / \mathrm{Pbl}_{2}$ films. UPS measurements have been acquired with a monochromatic VUV 5000 microwave UV source (VG Scienta) using the He la emission line $(21.22 \mathrm{eV})$ with a $-8 \mathrm{~V}$ sample bias and an analyzer pass energy of $2 \mathrm{eV}$. The photoelectron BE scale is calibrated using the Fermi edge $(0.00$ $\mathrm{eV})$ and $\mathrm{Au} 4 \mathrm{f}_{7 / 2}$ peak $(84.00 \mathrm{eV})$ of a sputter-cleaned gold sample. Due to significantly faster acquisition times for UPS scans, three measurements $(n=3)$ have been taken at different spots per nominal thickness to yield statistics for the reported work function $(\Phi)$ and valence band maximum energies (EvBM). We did not observe any change in BE or shape of the XPS CL or UPS VB/SECO spectra for any of the samples during analysis with UV or X-ray irradiation. XPS spectra are processed using CasaXPS software according to previously described procedures. ${ }^{4}$ 
Co-evaporation of $\mathrm{MAl}$ and $\mathrm{Pbl}_{2}$ Films. The thermal co-evaporation of $\mathrm{MAPbl}_{3} /$ precursor films onto $\mathrm{TiO}_{2}, \mathrm{APTES}-\mathrm{HCl}$ and APTES-KOH surfaces and subsequent PES characterization has been conducted over a two week period. The procedures are very similar to a previous report. ${ }^{4}$ Briefly, MAI and $\mathrm{Pbl}_{2}$ are evaporated from two separate quartz Knudsen cells in the growth chamber (base pressure ca. $5 \times 10^{-8} \mathrm{mbar}$ ) at rates of $0.60 \AA / \mathrm{s}$ (ca. $120^{\circ} \mathrm{C}$ ) and $0.40 \AA / \mathrm{s}$ (ca. $300^{\circ} \mathrm{C}$ ) at a pressure of ca. $4 \times 10^{-4} \mathrm{mbar}$, respectively. After deposition, the films are transferred without breaking vacuum to the preparation chamber (ca. $5 \times 10^{-9} \mathrm{mbar}$ ) and annealed at $70^{\circ} \mathrm{C}$ for 1 hour. After cooling, the samples are transferred to the analysis chamber (base pressure in the low 10-10 mbar range) for PES measurements. Initially, equal nominal precursor/MAPbl ${ }_{3}$ film thicknesses (i.e., 2, 8, 10, 20, 50, 100 and $200 \mathrm{~nm}$ ) have been sequentially and simultaneously deposited on all three $\mathrm{TiO}_{2}$ contacts and subsequently characterized with PES. After immediate evaluation of these initial PES results, intermediate nominal precursor/MAPbl ${ }_{3}$ film thicknesses (i.e., $3.5 \mathrm{~nm}$ and $5 \mathrm{~nm}$ on the aminosilane-modified $\mathrm{TiO}_{2}$ contacts and $6 \mathrm{~nm}$ and $15 \mathrm{~nm}$ on the bare $\mathrm{TiO}_{2}$ contact) have been deposited on fresh substrates to enrich the data density during initial film growth and $\mathrm{MAPbl}_{3}$ nucleation, which is significantly different for the bare $\mathrm{TiO}_{2}$ and aminosilane-modified $\mathrm{TiO}_{2}$ contacts.

Electron ionization quadrupole mass spectrometry (El-QMS). The obtained with a residual gas analyzer (Pfeiffer, $m / z$ range of 0-100 amu) during thermal co-evaporation of MAl and $\mathrm{Pbl}_{2}$ from separate quartz Knudsen cells in the precursor growth chamber at a pressure of ca. $4 \times 10^{-4}$ mbar. The MAI deposition temperature and rate are ca. $120{ }^{\circ} \mathrm{C}$ and 0.60 $\AA / s$, respectively. The $\mathrm{Pbl}_{2}$ deposition temperature and rate are ca. $300^{\circ} \mathrm{C}$ and $0.40 \AA / s$, respectively.

Solution-processed $\mathrm{MAPbI}_{3}$ and $\mathrm{MABr}$-doped $\mathrm{FAPbl}_{3}$. PALs are solution-processed inside a $\mathrm{N}_{2}$ glovebox $(<0.1 \mathrm{ppm}$ $\mathrm{H}_{2} \mathrm{O}$, < $1.0 \mathrm{ppm} \mathrm{O}_{2}$ ) using a previously-reported intramolecular exchange process with minor modifications. ${ }^{2} \mathrm{~A}$ 1:1::DMSO: $\mathrm{Pbl}_{2}$ adduct stock solution $(1.3 \mathrm{M}, 10 \mathrm{~mL})$ is prepared in DMF by heating and stirring overnight at $70{ }^{\circ} \mathrm{C}$. The stock solution is stored in the $\mathrm{N}_{2}$ box at RT. Approximately one hour prior to film processing, an aliquot of the RT stock solution is filtered $\left(0.25 \mu \mathrm{m}\right.$ PTFE) and heated to $105^{\circ} \mathrm{C}$. Just prior to film processing, stock solutions of MAI (75 $\mathrm{mg} / \mathrm{mL}, 0.572 \mathrm{M}), \mathrm{FAl}(110 \mathrm{mg} / \mathrm{mL}, 0.640 \mathrm{M})$ and $\mathrm{MABr}(25 \mathrm{mg} / \mathrm{mL}, 0.223 \mathrm{M})$ salts are dissolved in ultra-dry isopropanol (i.e., sequentially dried and stored over $20 \% \mathrm{~m} / \mathrm{v} 3 \AA$ molecular sieves for at least a week prior to use) by heating at 70 ${ }^{\circ} \mathrm{C}$ for ca. $3 \mathrm{~min}$; after cooling to RT (ca. $\left.10 \mathrm{~min}\right)$, the solutions are filtered (0.25 $\mu \mathrm{m}$ PTFE) and diluted with IPA in proper proportions to afford MAI (60-75 mg/mL; 0.377-0.472 M) and 15 mol\% MABr w.r.t. FAl (60-75 mg/mL FAl; 0.401$0.502 \mathrm{FAl}+\mathrm{MABr}$ ) solutions. An aliquot of heated $\mathrm{Pbl}_{2}$ :DMSO adduct solution $\left(15 \mu \mathrm{L} / \mathrm{cm}^{2}\right)$ is quickly dispensed on the room temperature substrate and spun at $6000 \mathrm{rpm}(6000 \mathrm{rpm} / \mathrm{s}, 30 \mathrm{~s})$. Immediately after the film is at rest, an aliquot of the RT organohalide salt solution $\left(35 \mu \mathrm{L} / \mathrm{cm}^{2}\right)$ is dispensed onto the adduct film and spun off (6000 rpm, $\left.10 \mathrm{~s}\right)$ after a ca. 2-3 s rest time. After performing a thorough purge of the $\mathrm{N}_{2}$ box to mitigate the presence of residual solvent vapor, the films are annealed $\left(11{ }^{\circ} \mathrm{C}\right.$ for $\mathrm{MAPbl}_{3}$ and $150{ }^{\circ} \mathrm{C}$ for $\mathrm{MABr}$-doped $\left.\mathrm{FAPbl}_{3}\right)$ on a hot plate in covered, $100 \mathrm{~mm}$ petri dishes for an hour. After cooling to RT, PMMA (15 mg/mL in chlorobenzene, $20 \mu \mathrm{L} / \mathrm{cm}^{2}$ ) is coated (4000 rpm, $20 \mathrm{~s}$ ) onto the films prior to XRD measurements in ambient.

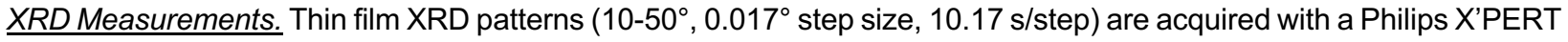
MPD system using Cu K $\alpha$ radiation $(45 \mathrm{~V}, 40 \mathrm{~mA})$. The incident beam is passed through a divergence slit $\left(0.5^{\circ}\right)$, antiscatter slit $\left(1.0^{\circ}\right)$ and mask (fixed $10 \mathrm{~mm}$ ). Replicate measurements $(n=3-4)$ on different sample areas have been made to calculate statistics. The XRD patterns are background subtracted with a spline function and fit with an asymmetric Pearson VII function to obtain the peak position, FWHM and intensity. The crystallite coherence length $\left(L_{C}\right)$ is determined using the Sherrer equation, where the instrumental broadening under identical resolution conditions is determined using a Si (100) wafer standard. 


\section{SI Figures:}

Table S1: Estimated Thickness/Coverage of APTES on $\mathrm{TiO}_{2}$ as a Function of Treatment Sample $\quad \mid \mathbf{t}$,Thickness $(\mathrm{A})^{\mathrm{a}} \mid$ Coverage $(\% \mathrm{ML})^{b} \mid \Delta$ Coverage $(\%)^{c}$

\begin{tabular}{c|c|c|c}
\hline APTES-AD & $4.7 \pm 0.3$ & $55 \pm 4$ & N/A \\
APTES-HCl & $3.5 \pm 0.3$ & $41 \pm 4$ & $-26 \pm 3$ \\
APTES-KOH & $4.4 \pm 0.2$ & $52 \pm 2$ & $-6 \pm 2$
\end{tabular}

${ }_{t}^{a}=\ln \frac{I_{0}}{I} \lambda_{n, \pi} \cos p(\theta)$, where $I_{0}$ and $l$ is the integrated Ti $2 p$ intensity of bare $\mathrm{TiO}_{2}$ and after APTES treatment, respectively. (values for $\left.\theta=0^{\circ}, n=6\right)$

${ }^{\circ}$ Coverage w.r.t. an upright and close-packed APTES monolayer (thickness $\approx 8.5 \AA$ )

'Coverage change w.r.t. as-deposited APTES (APTES-AD) 

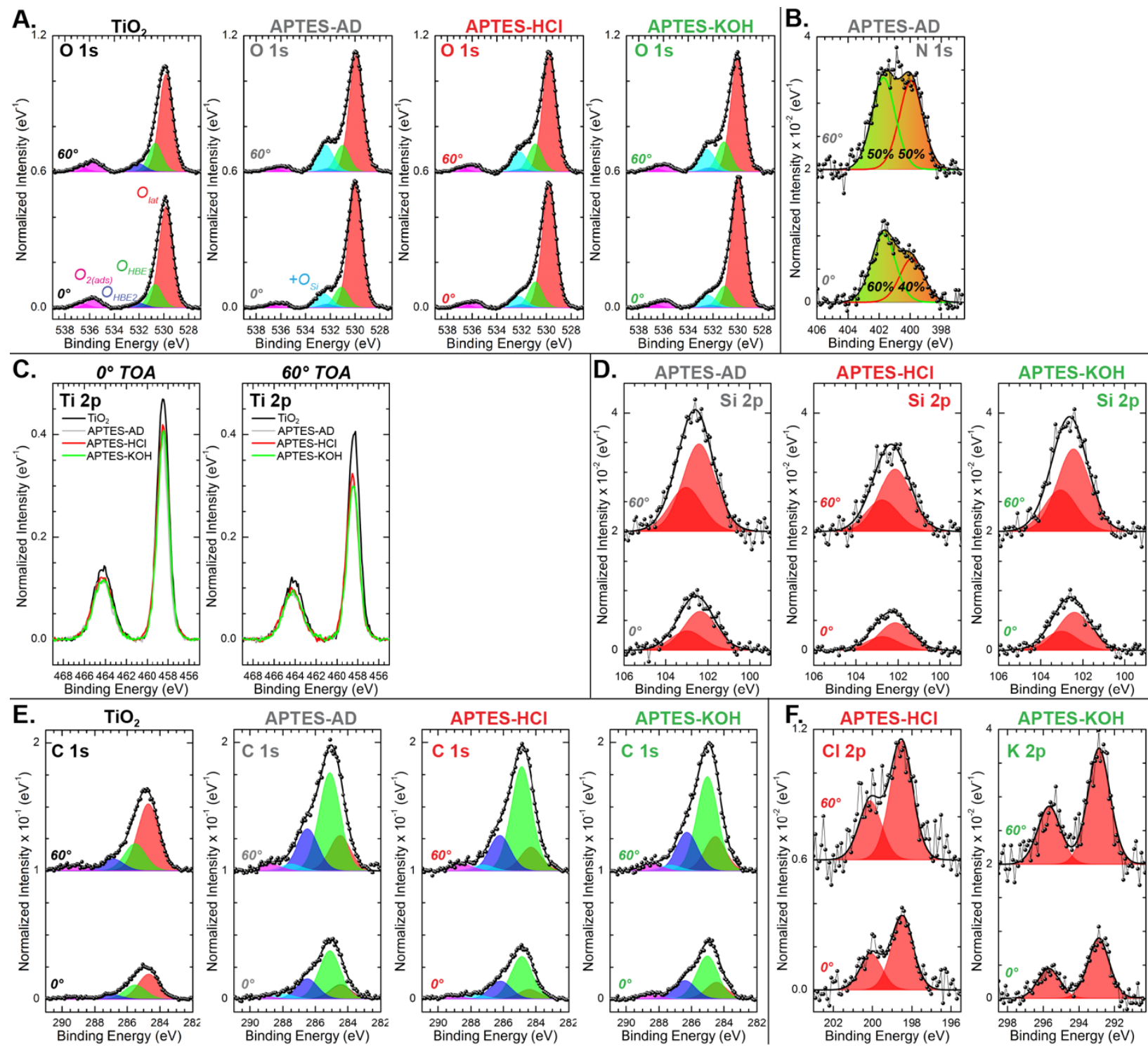

Figure S1. Representative AR-XPS CL spectra for bare and APTES-modified $\mathrm{TiO}_{2}$ samples at a TOA of $0^{\circ}$ (more bulksensitive) and $60^{\circ}$ (more surface-sensitive). APTES- $\mathrm{HCl}$ and APTES-KOH samples are compared with as-deposited APTES (APTES-AD). The CL spectra have been normalized to the angle- and sample-specific integrated Ti $2 p$ intensity. (A) $\mathrm{O} 1 \mathrm{~s} \mathrm{CL}$ spectra. Bare $\mathrm{TiO}_{2}$ is deconvoluted with four peaks: the low $\mathrm{BE}$ peak and high $\mathrm{BE}$ doublet is confidently assigned to lattice oxygen $\left(\mathrm{O}_{\text {lat }}\right)$ and physisorbed oxygen $\left(\mathrm{O}_{2(\mathrm{ads})}\right)$, respectively. ${ }^{5}$ High $\mathrm{BE}$ shoulder $\left(\mathrm{O}_{\text {HBE1 }}\right.$ and $\mathrm{O}_{\mathrm{HBE}}$ ) fitting components have previously been attributed to surface-confined adventitious carboxylate, ${ }^{6}$ unique hydroxyl $\mathrm{l}^{7}$ and superoxide ${ }^{8}$ species. APTES modification requires an additional fitting component attributed to bound and free silanol groups $\left(\mathrm{O}_{\mathrm{Si}}\right.$ ). Relative changes in the high BE shoulder after treatment (Fig. S2) suggest that $\mathrm{O}_{\text {HBE1 }}$ reports on protonated bridging oxygens $\left(\mathrm{OH}_{\mathrm{br}, 2 \mathrm{c}}\right)$ and $\mathrm{O}_{\text {HвE2 }}$ reports on superoxide $\left(\mathrm{O}_{2}{ }^{-}{ }^{-}\right.$(ads) $)$(B) N 1s CL spectrum for APTES-AD. (C) Ti $2 p$ CL spectra are normalized w.r.t. the integrated intensity of the bare $\mathrm{TiO}_{2}$ sample at a TOA of $0^{\circ}$. (D) Si $2 p$ CL spectra ( $F W H M=1.80 \mathrm{eV}, \Delta E_{P}=0.62 \mathrm{eV}, 2: 1$ area ratio for 3/2:1/2 peaks) for APTES-treated $\mathrm{TiO}_{2}$ samples. (E) $\mathrm{C} 1 \mathrm{~s} \mathrm{CL}$ spectra for bare and APTES-modified $\mathrm{TiO}_{2}$ samples. The spectra are deconvoluted (FWHM=1.50 eV for all fitting components) with up to 5 peaks. Notably, C 1 (red: adventitious aliphatic species) decreases while $\mathrm{C} 2$ (green: $\mathrm{C}-\mathrm{C} / \mathrm{C}-\mathrm{Si} / \mathrm{C}-\mathrm{NH}_{2}$ bonds) and $\mathrm{C} 3$ (blue: $\mathrm{C}-\mathrm{NH}_{3}{ }^{+}$or $\mathrm{C}$ bonded to other electron electron-deficient $\mathrm{N}$ atoms, such as $\mathrm{H}-$ bond acceptor or coordinate covalent bonds between the amine and undercoordinated Ti atoms) increases after APTES adsorption (see Fig. S2). (F) Cl 2p CL spectra ( $F W H M=1.32 \mathrm{eV}, \Delta \mathrm{E}_{\mathrm{p}}=1.60 \mathrm{eV}, 2: 1$ area ratio for 3/2:1/2 peaks) for APTES- $\mathrm{HCl}$ and $\mathrm{K} 2 \mathrm{p}$ CL spectra ( $F W H M=1.45 \mathrm{eV}, \Delta \mathrm{E}_{\mathrm{P}}=2.80 \mathrm{eV}, 2: 1$ area ratio for 3/2:1/2 peaks) for APTES-KOH. 
A.

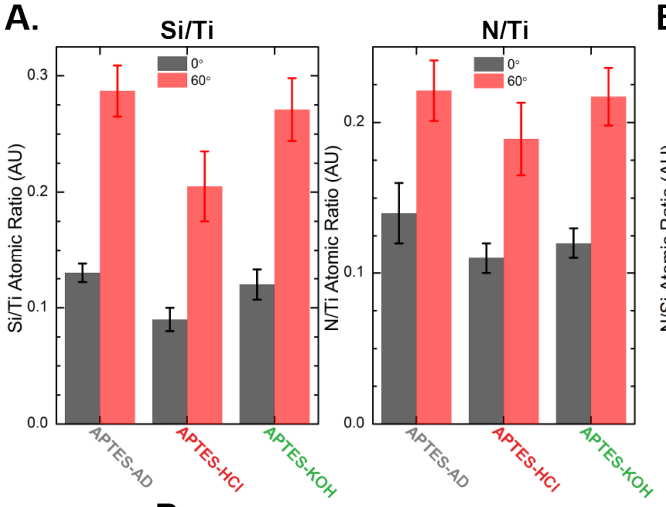

D.

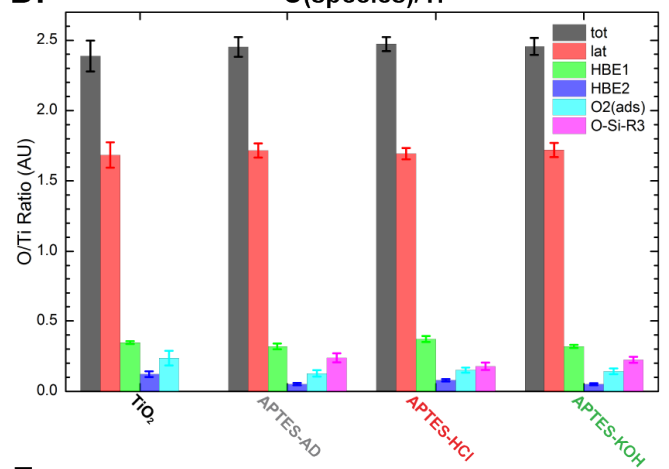

F.

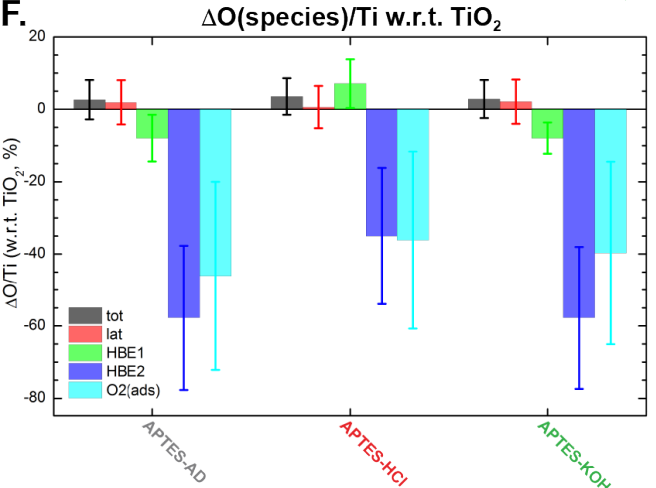

B.

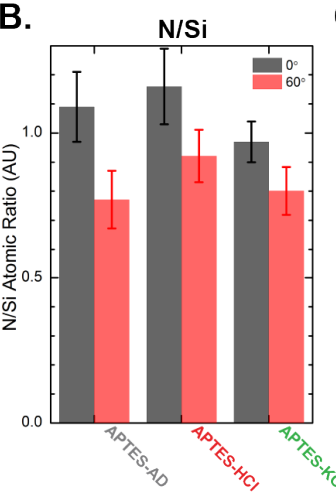

E.

C. CI/Si:APTES-HCl

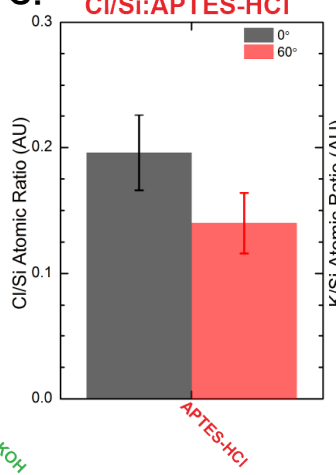

C(species) $/ \mathrm{Ti}$

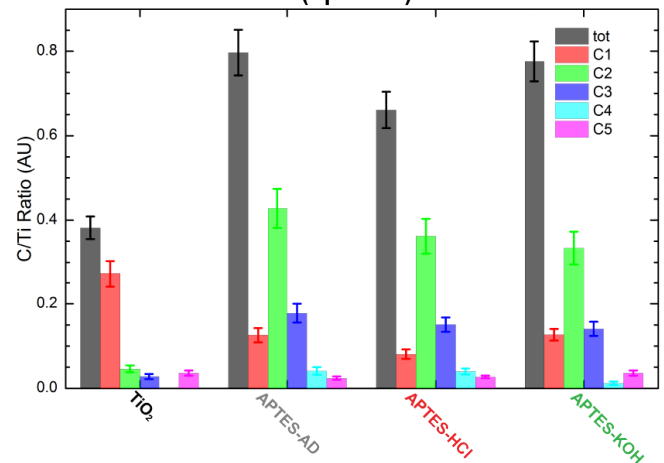

G.

$\Delta \mathrm{C}$ (species)/Ti w.r.t. $\mathrm{TiO}_{2}$

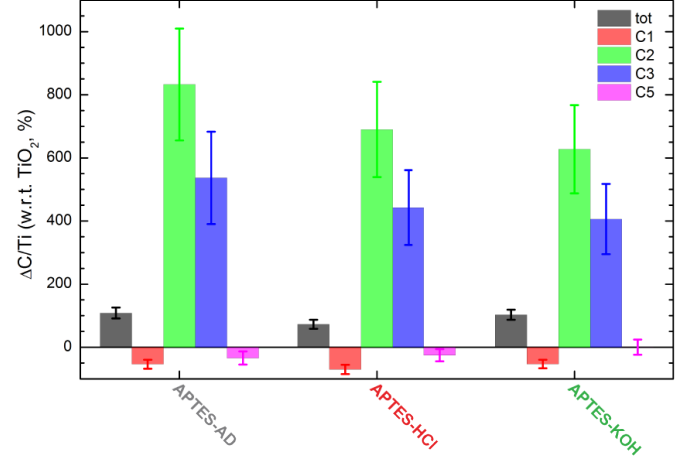

Figure S2. Quantification of atomic ratios from deconvoluted AR-XPS (TOA of $0^{\circ}$ and $60^{\circ}$ ) data in Fig. S1. Uncertainties are determined by replicate measurements $(n \geq 3)$ and propagated throughout all calculations. (A) AR-XPS Si/Ti and $\mathrm{N} / \mathrm{Ti}$ atomic ratios for APTES-AD, APTES-HCl and APTES-KOH samples. (B) AR-XPS N/Si atomic ratios for APTESAD, APTES-HCl and APTES-KOH samples. (C) AR-XPS Cl/Si and $\mathrm{K} / \mathrm{Si}$ ratios for APTES-HCl and APTES-KOH samples, respectively. (D,E). Species-dependent $\mathrm{O} / \mathrm{Ti}(\mathrm{D})$ and $\mathrm{C} / \mathrm{Ti}(\mathrm{E})$ atomic ratios at $0^{\circ}$ determined from deconvoluted $\mathrm{CL}$ spectra. $(\mathbf{F}, \mathbf{G})$ Relative change in the species-dependent $\mathrm{O} / \mathrm{Ti}(\mathrm{F})$ and $\mathrm{C} / \mathrm{Ti}(\mathrm{G})$ atomic ratios at $0^{\circ}$ w.r.t. the bare $\mathrm{TiO}_{2}$ surface, as calculated according to eq $\mathrm{S} 1$ (note: the same calculation is used to determine the relative change in TOA-dependent atomic ratios w.r.t. $0^{\circ}$ in Fig. 1).

$$
\Delta \text { Atomic Ratio w.r.t. } \mathrm{TiO}_{2}=\frac{\left(\text { Ratio }_{\text {Aminosilane }} \text { Ratio }_{\text {TiO2 }}\right)}{\text { Ratio }_{\text {TiO }}} \times 100 \% \text { (S1) }
$$

These relative changes in the $O 1 \mathrm{~s}$ and $C 1 \mathrm{~s}$ fitting components are used to evaluate possible species associated with high BE $O$ 1s shoulder fitting components (i.e., $\mathrm{O}_{\text {HBE1 }}$ and $\mathrm{O}_{\text {HBE2 }}$ ). (F) Notably, larger relative decreases in the $\mathrm{O}_{\text {HBE2 }}$ peak for APTES-AD and APTES-HCl, which are associated with a ca. $0.2 \mathrm{eV}$ Ti $2 p$ and $O$ 1s BE, implies that $O_{\text {HBE2 }}$ reports on adsorbed superoxide. ${ }^{8}$ Additionally, an increase in the $\mathrm{O}_{\text {HBE1 }}$ peak after $\mathrm{HCl}$ treatment suggests that this peak reports on protonated surface oxygens $\left(\mathrm{OH}_{\mathrm{br}, 2 \mathrm{C}}\right)$. (G) Similarly, a relative decrease in the $\mathrm{C}$ 1s $\mathrm{C} 5$ peak, which is related to surface carboxylate groups that are associated with the $O$ 1s HBE shoulder, ${ }^{6}$ indicates that these changes in the $\mathrm{O} 1 \mathrm{~s} \mathrm{HBE}$ shoulder are not due to changes in the coverage of adventitious carboxylate species. 


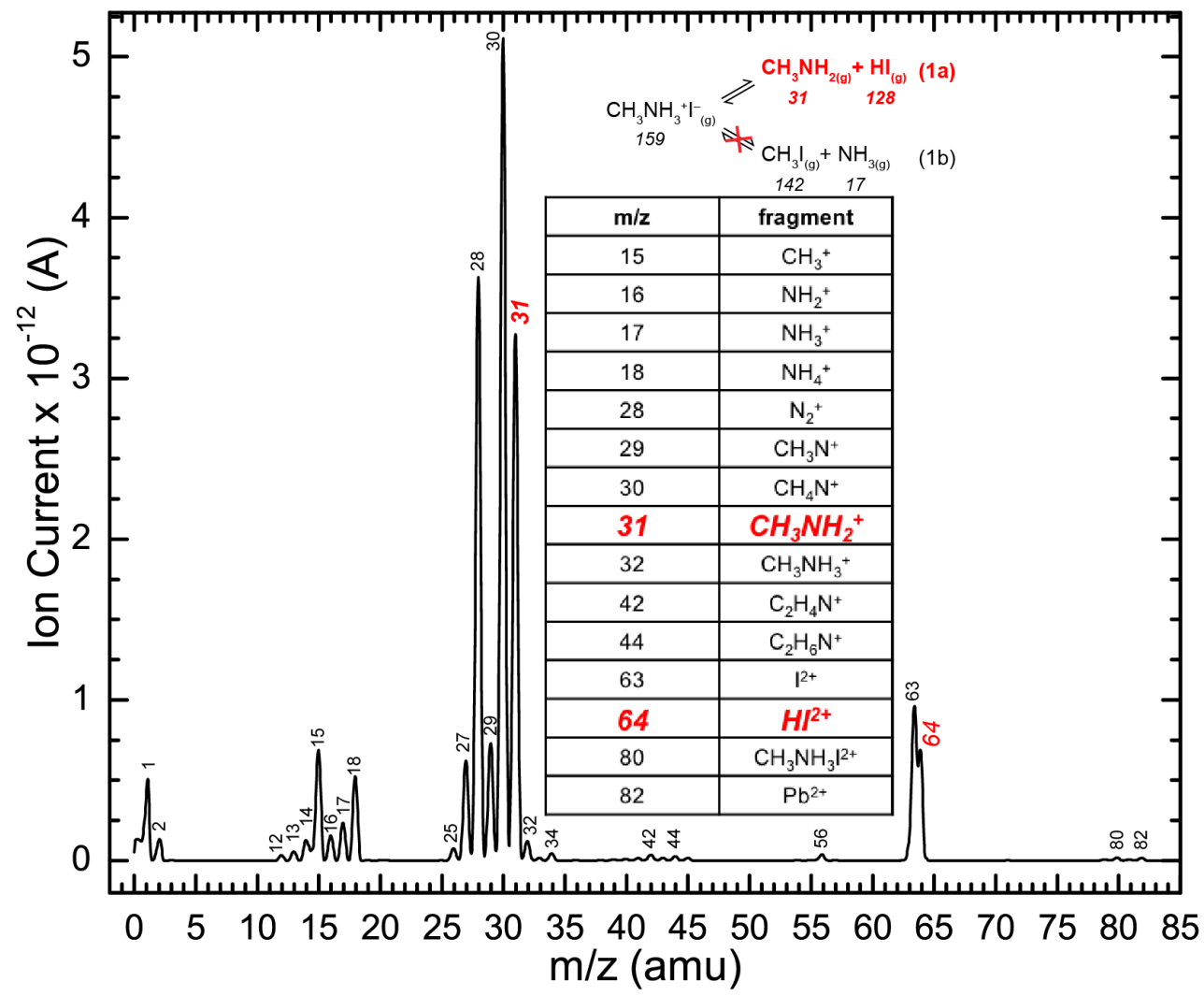

Figure S3. Electron ionization quadrupole mass spectrometry (El-QMS) analysis during thermal co-evaporation of $\mathrm{Pbl}_{2}$ and MAI from separate quartz crucibles. The primary and noteworthy fragments up to a $\mathrm{m} / \mathrm{z}$ of 63 amu are assigned in the table inset according to the literature. ${ }^{9-10}$ Contrary to reports by Qi and co-workers, ${ }^{9}$ thermal sublimation of MAI powder from a quartz Knudsen cell results in an intense peak at a $\mathrm{m} / \mathrm{z}$ of 31 amu (highlighted in red), which supports the presence of the methylamine parent molecule and suggests that dissociation reactions initiated by $\mathrm{Al}_{2} \mathrm{Al}_{2} \mathrm{O}_{3}$ crucible/support in Qi's investigation is likely responsible for their proposed gas-phase degradation pathways of $\mathrm{MAI} / \mathrm{MAPbl}_{3}$. According to Luther and co-workers, ${ }^{10}$ we assign the intense peak at a $\mathrm{m} / \mathrm{z}$ of 63 amu to an $\mathrm{I}^{2+}$ fragment. We suggest that the peak at a $\mathrm{m} / \mathrm{z}$ of 64 amu corresponds to the $\mathrm{HI}^{2+}$ parent fragment. We also observe a weak peak at a $\mathrm{m} / \mathrm{z}$ of 80 amu that we assign to $\left.\mathrm{CH}_{3} \mathrm{NH}_{3}\right|^{2+}$ complex and a weak peak at $m / z$ of 82 amu that is tentatively assigned to $\mathrm{Pb}^{2+}$. Gas-phase equation (1a), which is shown in the inset here, is supported by this MS analysis. The numbers in italics below the MAI reactant and products in equation (1a) and (1b) above correspond to the molecular weight of the compounds in $\mathrm{g} / \mathrm{mol}$. 

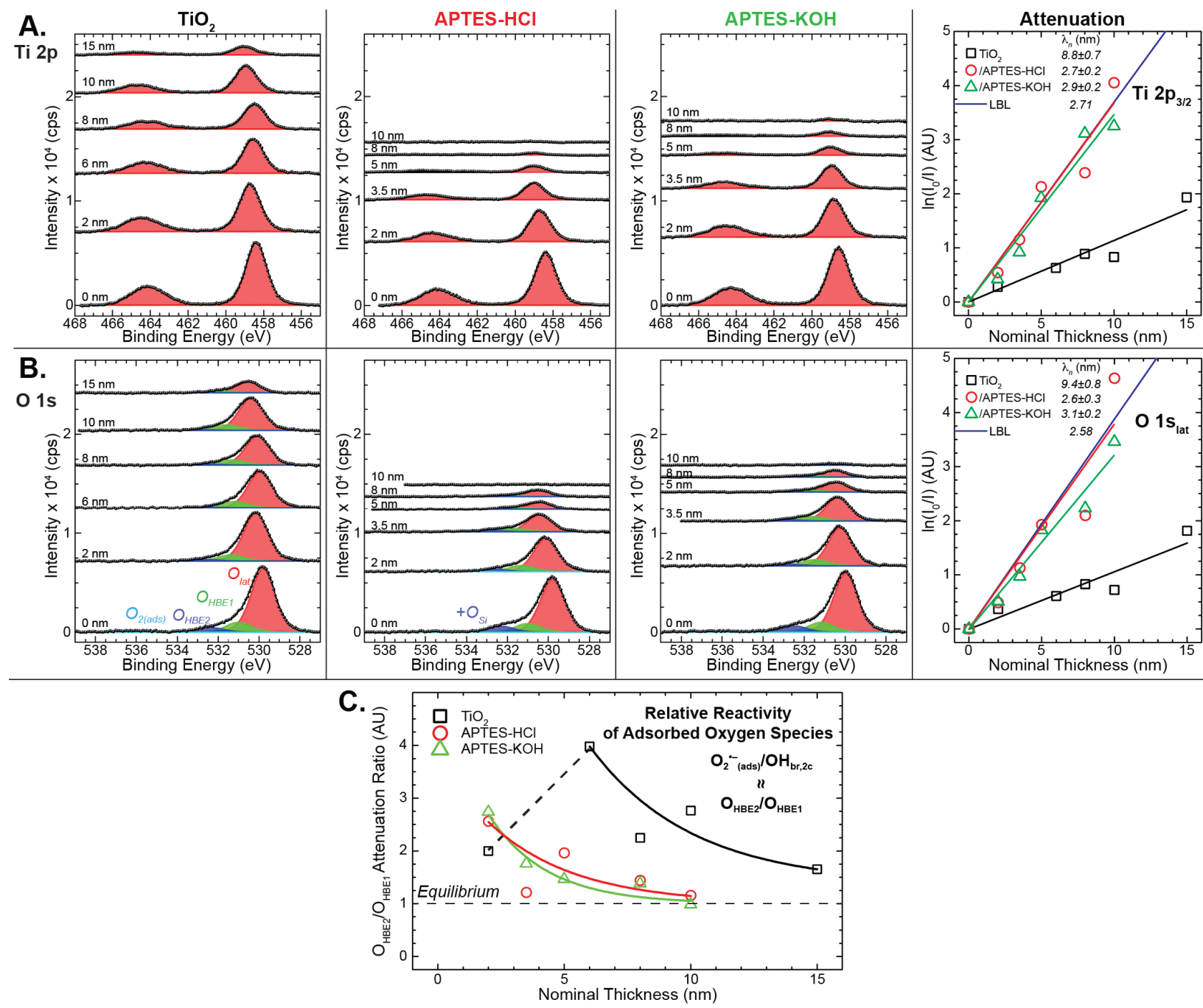

Figure S4. Attenuation of Ti 2p (A) and O 1s (B) XPS CL spectra as a function of nominal precursor thickness on $\mathrm{TiO}_{2}$, APTES-HCl and APTES-KOH samples. The measured inelastic mean free path $\left(\lambda_{n}\right)$ is compared with the expected value for layer-by-layer (LBL) growth, as shown in Fig. 3 of the main text. (C) The attenuation ratio of the high BE O 1s fitting components ( $\mathrm{O}_{\mathrm{HBE} 2}$ and $\mathrm{O}_{\mathrm{HBE}}$, which report on $\mathrm{O}_{2}{ }^{-{ }^{-}}$(ads) and $\mathrm{OH}_{\mathrm{br}, 2 \mathrm{c}}$, respectively - see Fig. S2) during film growth provides information on the relative population of the corresponding adsorbed species. We suggest that high initial $\mathrm{O}_{\mathrm{HBE} 2} / \mathrm{O}_{\text {HBE1 } 1}$ ratios suggest that superoxide readily desorbs while bridging oxygens are protonated due to $\mathrm{HI}$ dissociation; this ratio generally decreases with film growth and approaches and equilibrium state that suggests full displacement of superoxide, which agrees with the positive shift and equilibration of the $T i 2 p_{3 / 2}$ and $O 1 s_{\text {lat }} C L B E$ in Fig. S7. 
$\mathrm{TiO}_{2}$
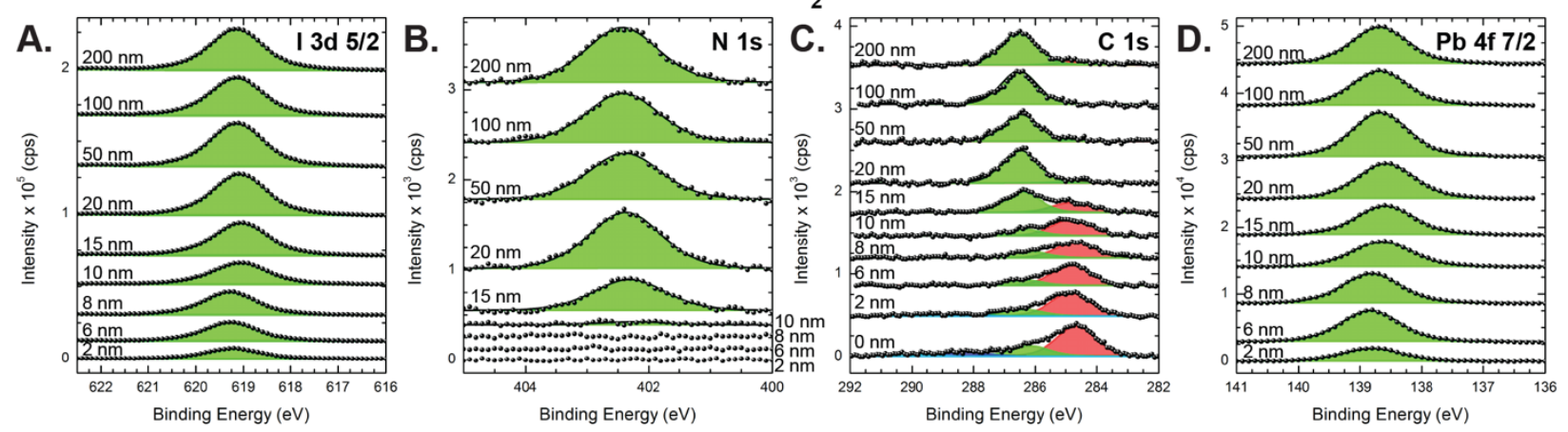

APTES-HCI
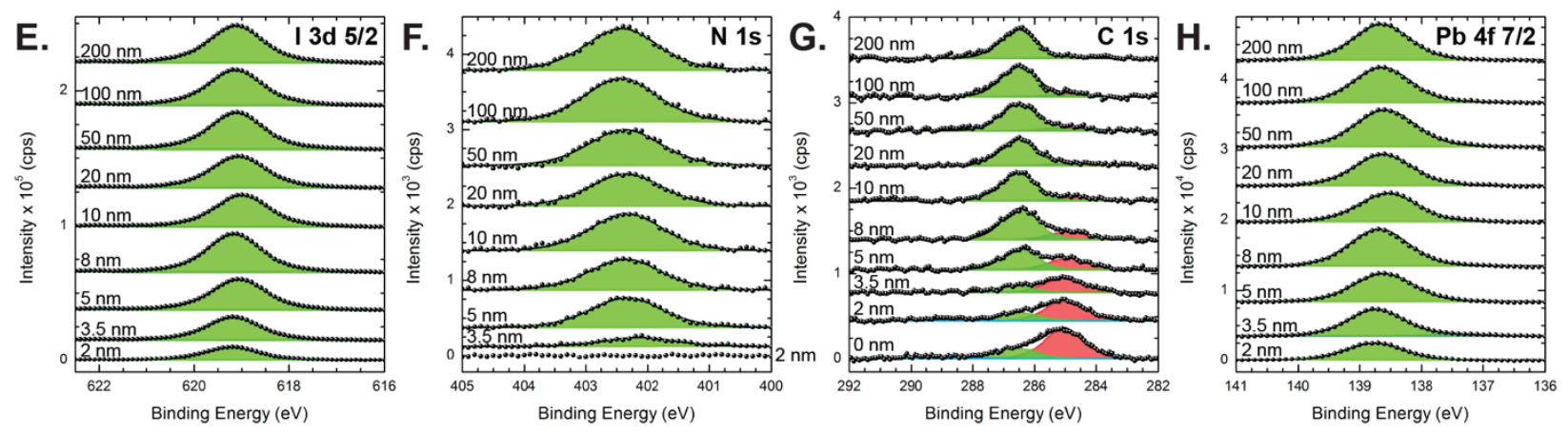

\section{APTES-KOH}
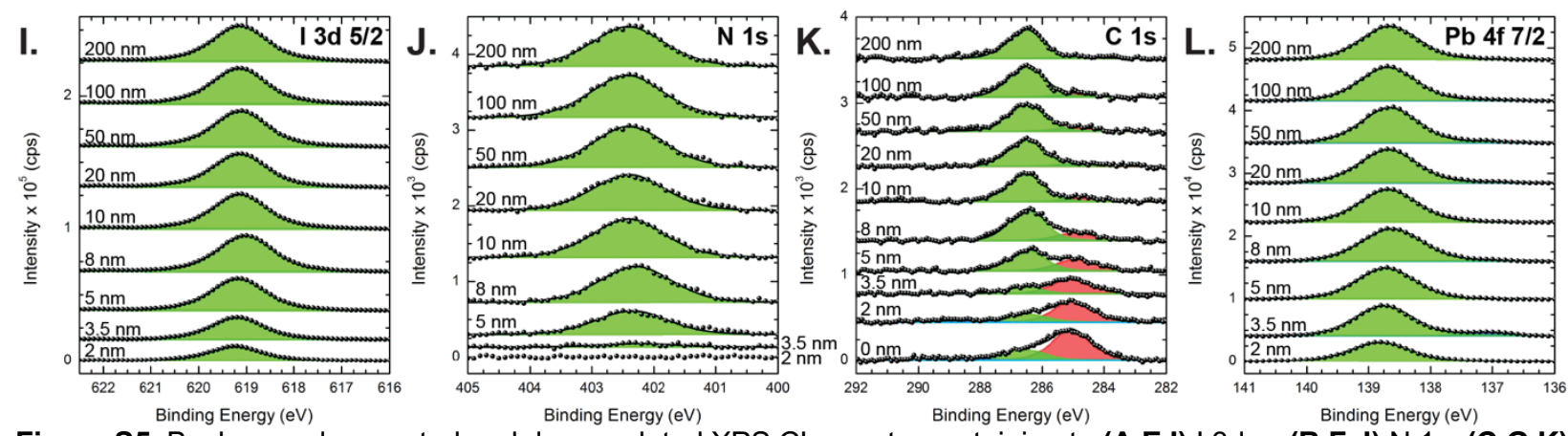

Figure S5. Background-corrected and deconvoluted XPS CL spectra pertaining to (A,E,I) I 3d $d_{5 / 2},(B, F, J) ~ N ~ 1 s,(C, G, K)$ $\mathrm{C} 1 \mathrm{~s}$ and $(\mathbf{D}, \mathrm{H}, \mathrm{L}) \mathrm{Pb} 4 \mathrm{f}_{7 / 2}$ on (A-D) $\mathrm{TiO}_{2},(\mathrm{E}-\mathrm{H})$ APTES-HCl and (I-L) APTES-KOH as a function of nominal precursor thickness. The corresponding thickness is shown next to each spectrum. Peak fits for components that are ascribed to PAL species are shaded in green.

Due to the presence of adsorbed adventitious carbon and aminosilane molecules, the $C$ 1s spectra for the nominally pristine substrates $(0 \mathrm{~nm})$ in $(\mathbf{C}, \mathbf{G}, \mathbf{K})$ have background signals near the methylammonium-related carbon $\left(\mathbf{C}-\mathrm{N}^{+}\right.$; $\mathbf{C}$ 1SPAL - shaded in green) found at a BE of ca. $285.6 \mathrm{eV}$. A low BE C 1s component, which decreases with increasing film thickness, is assigned to non-PAL carbon species ( $\mathrm{C}$ 1SnonPaL; e.g., $\mathrm{C}-\mathrm{H}, \mathrm{C}-\mathrm{C}, \mathrm{C}-\mathrm{I}$ and $\mathrm{C}-\mathrm{N}$ bonds) that result from adventitious species and possible methylammonium decomposition products (shaded in red). Due to the presence of two or more $\mathrm{C}$ 1s species, the $\mathrm{N}$ 1s atomic concentration provides a more reliable estimate of the near-surface MA concentration and $\mathrm{MA} / \mathrm{Pb}$ stoichiometry. We observe a low $\mathrm{BE}$ component $(\mathrm{BE}=136.9 \mathrm{eV})$ in the $\mathrm{Pb} 4 \mathrm{f}$ spectra $(\mathrm{D}, \mathrm{H}, \mathrm{L})$ that indicates a small relative concentration of metallic $\mathrm{Pb}$, which is barely visible for the $3.5 \mathrm{~nm}$ spectrum in (L). 
A.

$\mathrm{TiO}_{2}$
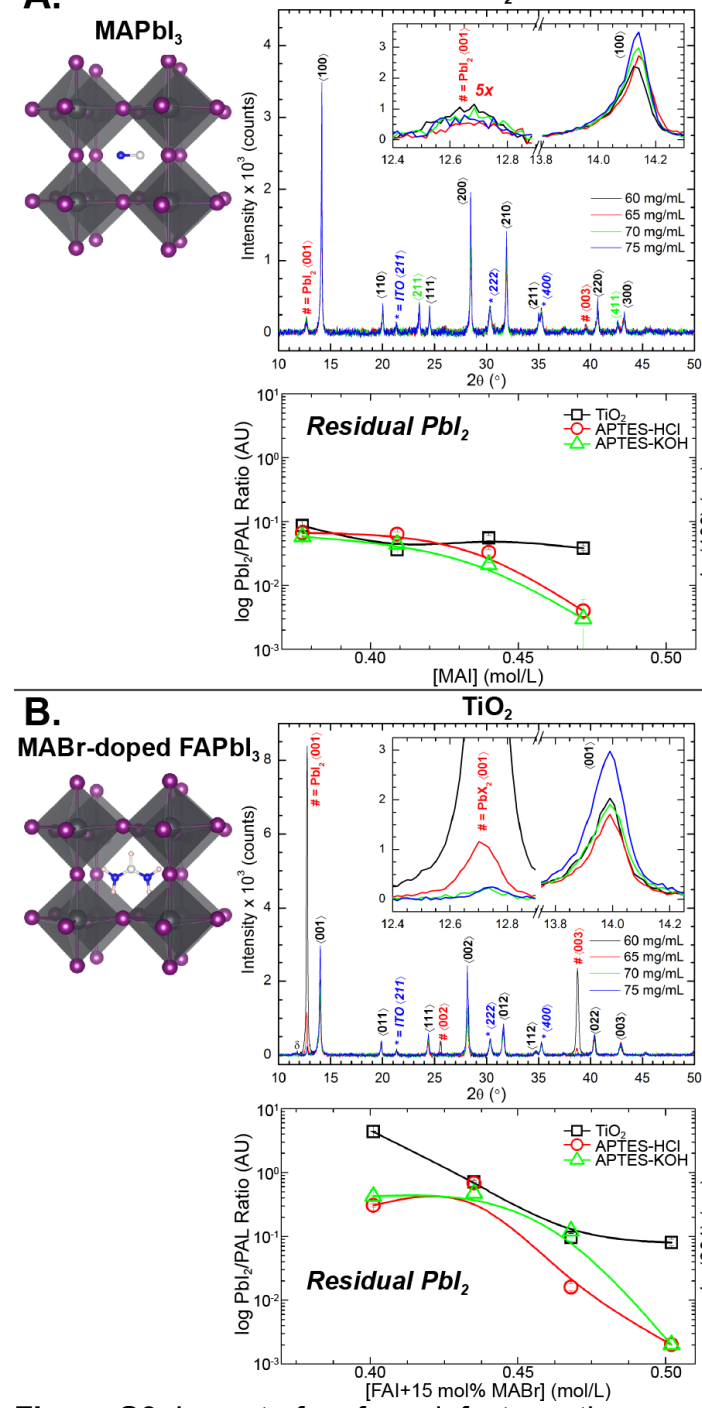

Figure S6. Impact of surface defects on the composition and structure of solution-processed PALs. (A) XRD analysis of cubic $\mathrm{MAPbl}_{3}(100)$ and (B) MABr-doped (15 mol\%) $\mathrm{FAPbl}_{3}$ (001) films as a function of organohalide salt concentration on $\mathrm{TiO}_{2}$, APTES-HCl and APTES-KOH surfaces. Decomposition of the organohalide salt on the unpassivated $\mathrm{TiO}_{2}$ contact is inferred from locally high $\mathrm{Pbl}_{2}(001) / \mathrm{PAL}$ intensity ratios that indicate the presence of residual $\mathrm{Pbl}_{2}$ within the $\mathrm{PAL}$ at the highest salt concentration. The coherence length $\left(L_{C}\right)$ of $\mathrm{PAL}$ and $\mathrm{Pbl}{ }_{2}$ crystallites provides a comparison of the average crystallinity. Reduced crystallinity of $\mathrm{Pbl}_{2}$ crystallites within PAL films on $\mathrm{TiO}_{2}$ and APTES-HCl samples indicates that incomplete surface passivation leads to enhanced surface reactivity, which produces decomposition products that perturb the crystallinity of unreacted $\mathrm{Pbl}_{2}$ driven to interfaces during PAL crystallization. The trend lines in all plots are a guide to the eye. 

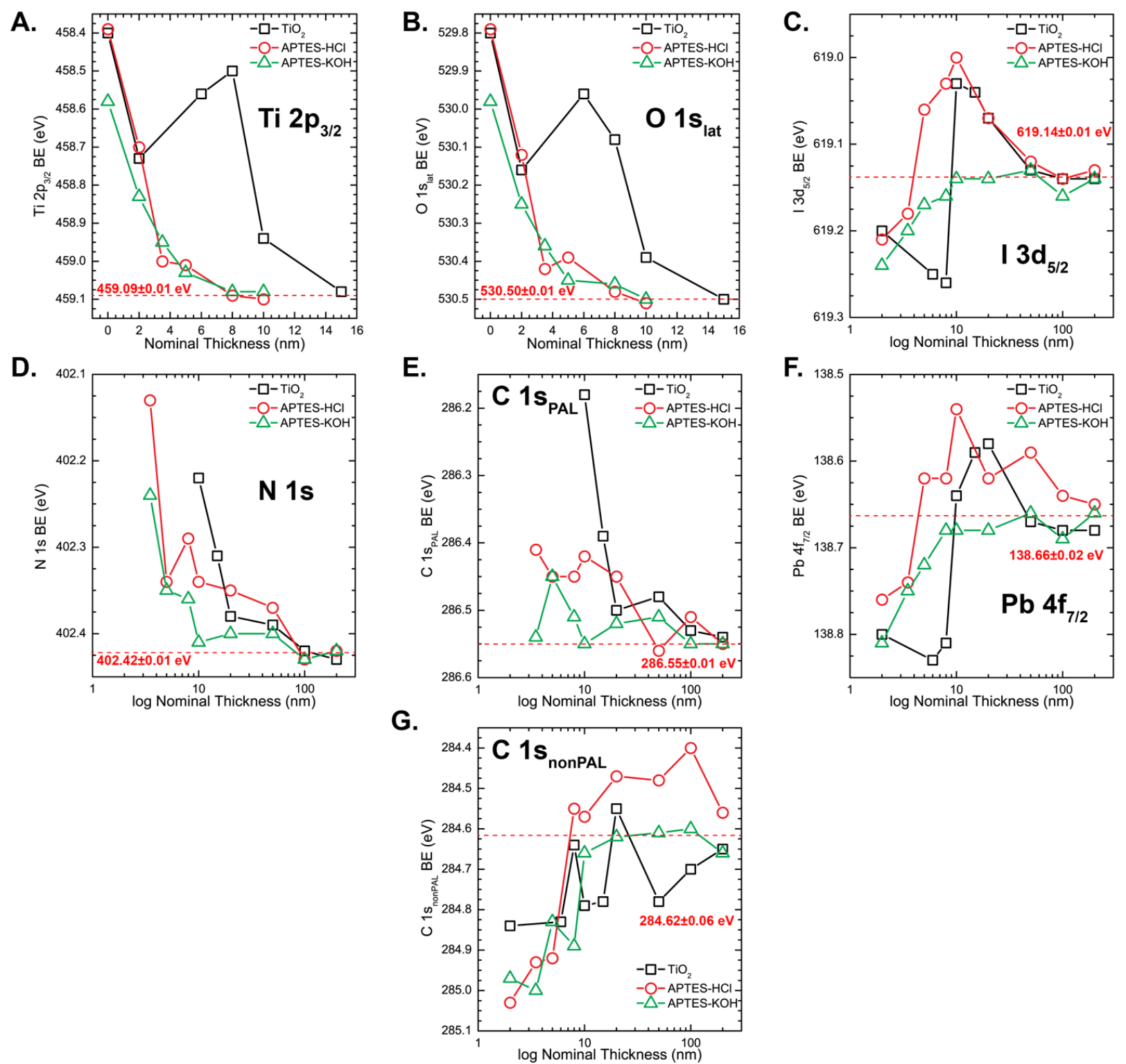

Figure S7. Thickness-dependent XPS CL BE for (A) O 1s lat, (B) Ti 2p $p_{3 / 2}$, (C) I 3d $d_{5 / 2}$, (D) N 1s, (E) C 1sPA, (F) Pb 4f $f_{7 / 2}$, and (G) C 1s nonPAL. The equilibrated CL BE (nominal thickness of $200 \mathrm{~nm}$ ) is averaged over all three samples, as indicated by the horizontal dashed line and reported with the corresponding standard deviation. 

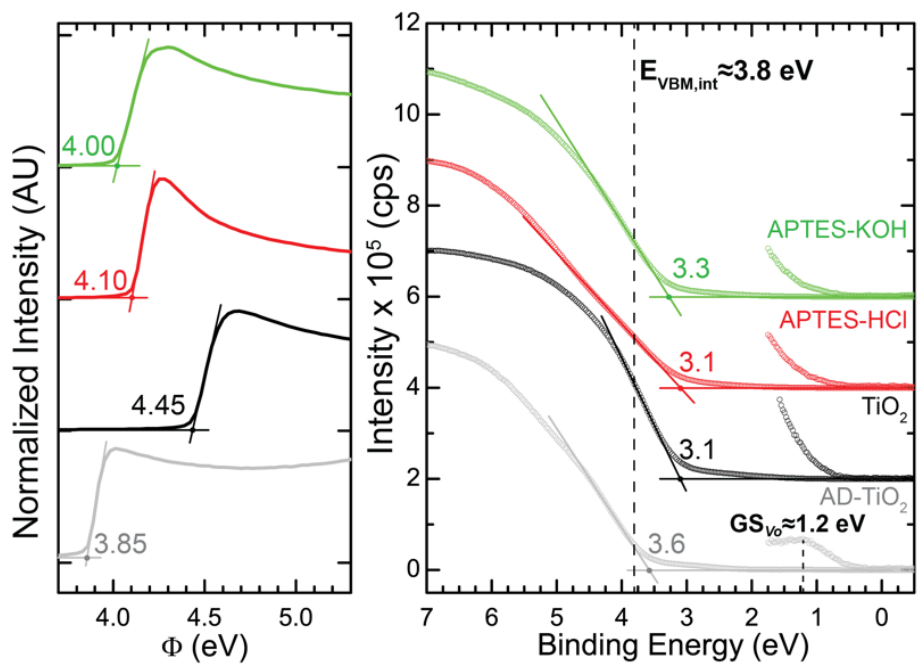

Figure S8. Representative UPS SECO (left panel) and VB (right panel) spectra of as-deposited $\mathrm{TiO}_{2}\left(\mathrm{AD}-\mathrm{TiO}_{2}\right.$, grey), oxygen plasma-treated $\mathrm{AD}-\mathrm{TiO}_{2}\left(\mathrm{TiO}_{2}\right.$, black), APTES-HCl (red) and APTES-KOH (green). The work function ( $\left.\Phi\right)$ and valence band maximum energy (EVBM) are determined by linear extrapolation of the SECO and VB onset, respectively, and shown on the graph. In addition, $E_{V B M}$,int, which is determined from the equilibrated Ti $2 p_{3 / 2}$ BE shift in Figs. S7 and S9, is shown as a dashed line. The $\mathrm{AD}-\mathrm{TiO}_{2}$ sample shows a clear feature associated with an oxygen vacancy related gap state $\left(G S_{V o}\right)$ near $1.2 \mathrm{eV} .{ }^{13}$ The increase in $\mathrm{E}_{\mathrm{VBM}}$ and $\mathrm{Ti} 2 \mathrm{p}_{3 / 2} \mathrm{BE}$ indicates electrochemical reduction of the $\mathrm{TiO}_{2}$ surface and must result in the reappearance of the oxygen vacancy-related gap state $\left(G S_{V_{0}}\right)$ seen for the $A D-T_{i O}$ sample at ca. $1.2 \mathrm{eV}$. 


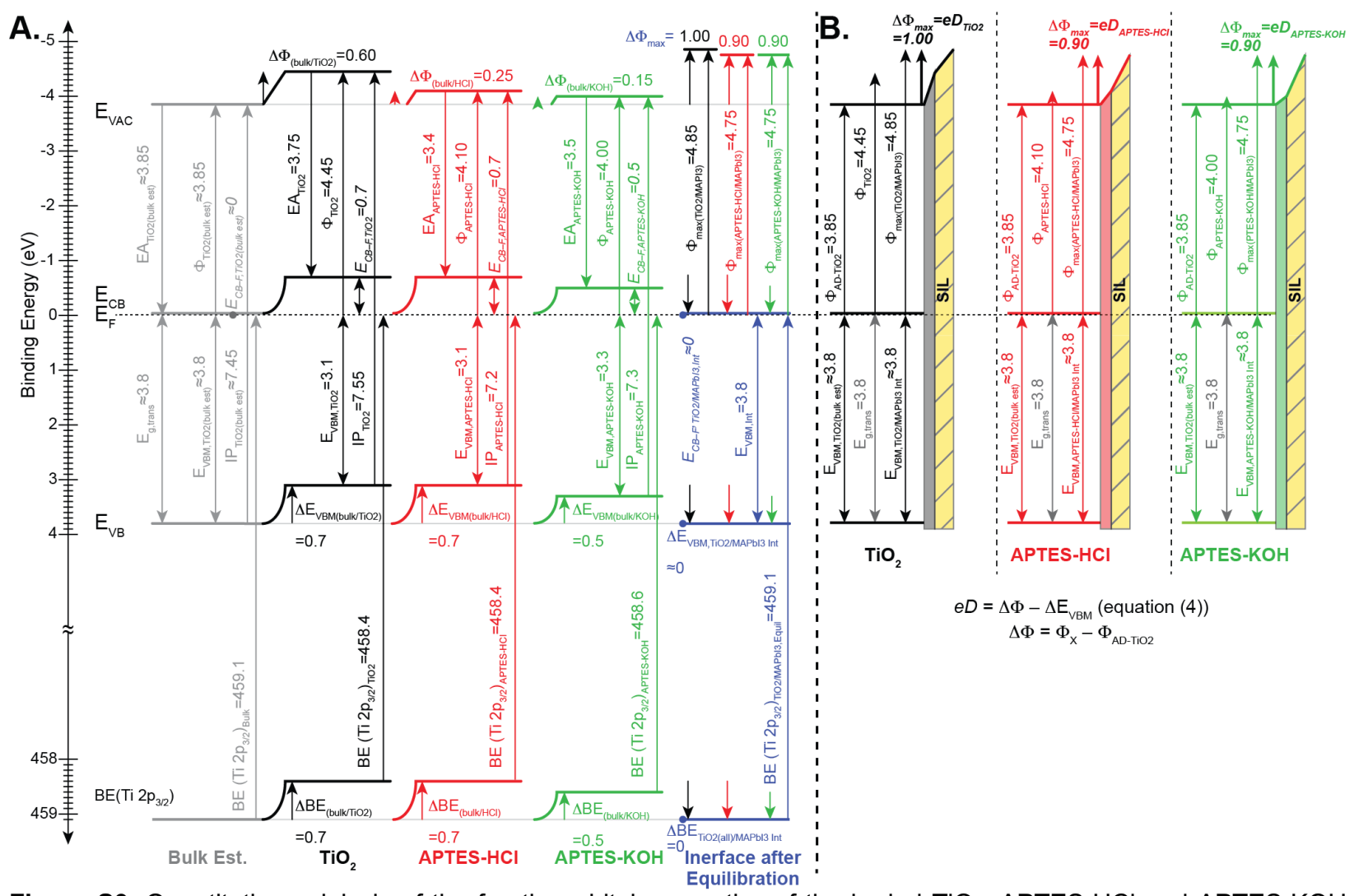

Figure S9. Quantitative anlalysis of the frontier-orbital energetics of the buried $\mathrm{TiO}_{2}, \mathrm{APTES}-\mathrm{HCl}$ and APTES-KOH substrate using the $\mathrm{BE}$ of the Ti $2 \mathrm{p}_{3 / 2} \mathrm{CL}$ (Fig. S7) and the UPS-derived $\mathrm{E}_{\mathrm{VBM}}$ and work function ( $\Phi$ ) values (Fig. S8). This treatment of the PES data reflects the fact that $C L$ and band-edge (VB and $C B$ ) energies are fixed with respect to each other and measured on a BE scale $\left(E_{F}=0 \mathrm{eV}\right.$ ). Therefore, BE shifts for CL (from XPS) and VB (from UPS) should be equal, and XPS BE energy shifts report on changes in the position of the transport levels with respect to the Fermi energy at the buried $\mathrm{TiO}_{2}$ interface. (A) Energy diagram showing the band-edge and $\mathrm{CL}$ ( $\mathrm{Ti} 2 \mathrm{p}_{3 / 2}$ ) $\mathrm{BE}$, along with the sample $\Phi$, for as-deposited $\mathrm{TiO}_{2}\left(\mathrm{AD}-\mathrm{TiO}_{2}\right.$, grey), which is used as a reference to estimate the bulk CVD-TiO 2 work function, $\mathrm{TiO}_{2}$ (black), APTES-HCl (red) and APTES-KOH (green) surfaces. The average $(n=9) \mathrm{Ti} 2 \mathrm{p}_{3 / 2}$ and $\mathrm{E}_{\mathrm{VBM}} \mathrm{BE}$ difference is constant $\left(\triangle \mathrm{BE}_{(\mathrm{Ti} 2 \mathrm{2p} 3 / 2-\phi)}=455.31 \pm 0.03 \mathrm{eV}\right)$. The blue levels on the right show the interface energetics for the $\mathrm{TiO}_{2}$, APTES-HCl and APTES-KOH that are extracted from the average $\mathrm{BE}$ of the $\mathrm{Ti} 2 \mathrm{p}_{3 / 2} \mathrm{CL}$ peak after equilibration $(459.09 \pm 0.01 \mathrm{eV})$ in Fig. S7. We estimate the interface $\mathrm{E}_{\mathrm{VBM} \text {,int }}$ for all three burried $\mathrm{TiO}_{2}$ contacts after equilibration with the co-evaporated $\mathrm{MAI} / \mathrm{Pbl}_{2}$ film to be $3.79 \pm 0.03 \mathrm{eV}$, which suggests that the $\mathrm{CVD}-\mathrm{TiO}_{2}$ transport gap ( $\mathrm{E}_{g, \text { trans }}$ ) is $3.8 \mathrm{eV}$ and that the $\mathrm{E}_{\mathrm{CB}}$ is pinned just above the Fermi energy for all $\mathrm{TiO}_{2}$ contacts. (B) Energy level diagrams for the buried $\mathrm{TiO}_{2}$ contacts after chemical/electronic equilabration and concomitant $e D$ formation, which is shown in Fig. 6 of the main text. We propose that pinning of $E_{C B}$ just above the Fermi energy translates to flat band conditions for all three $\mathrm{TiO}_{2}$ contacts. $e D_{\text {contact }}$ and $e D_{\text {MAPbl3 }}$ has been determined according to eqn (4). 
A.

$\mathrm{TiO}_{2}$

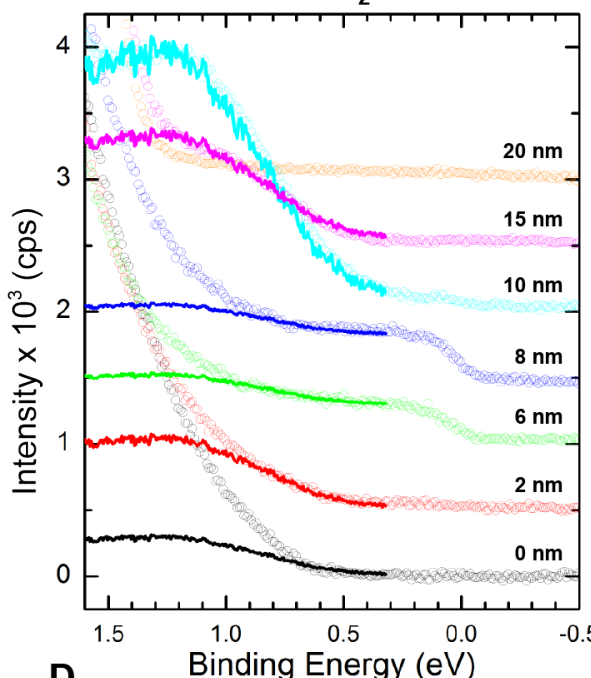

D.

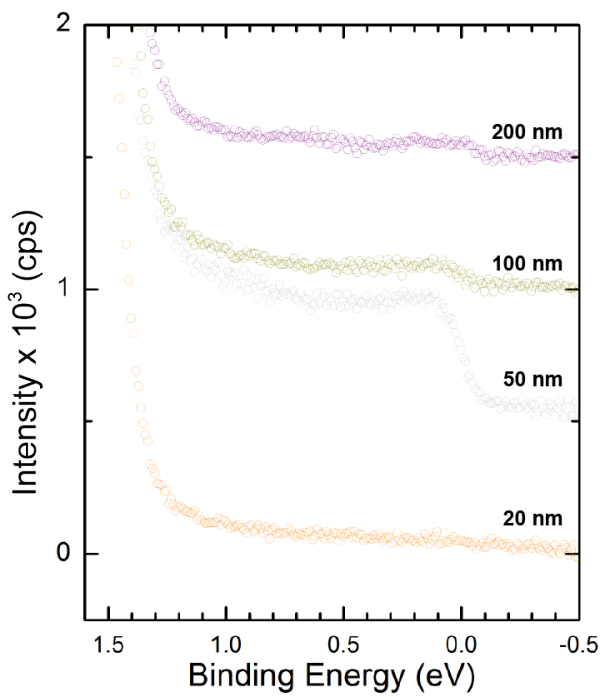

B.

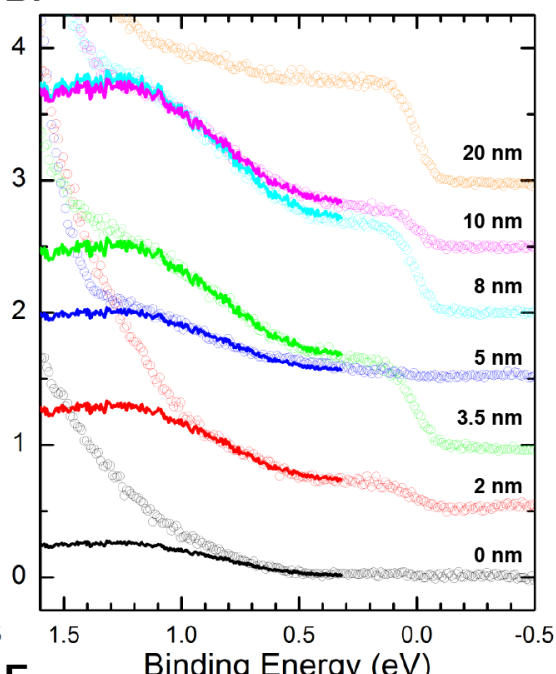

E.

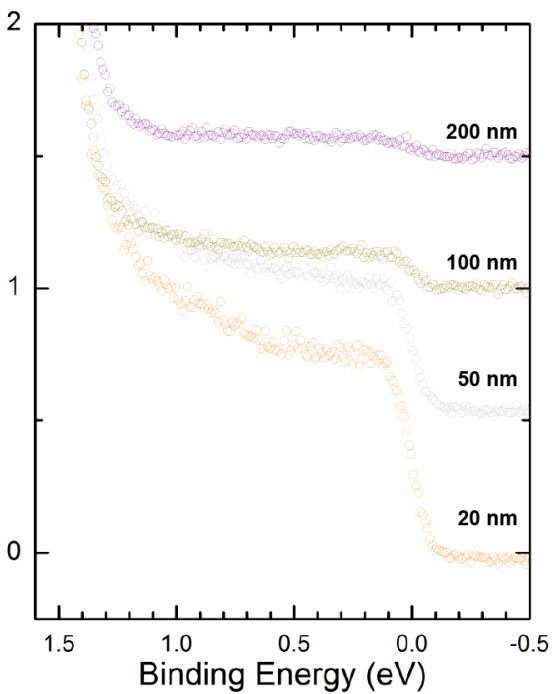

C.

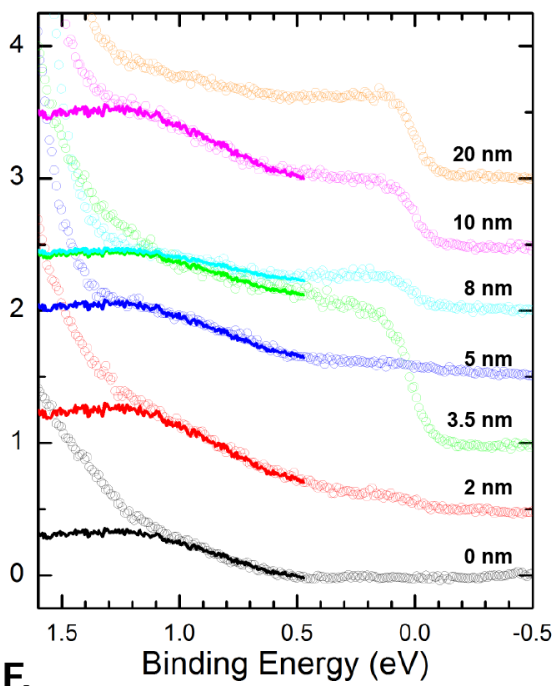

F.

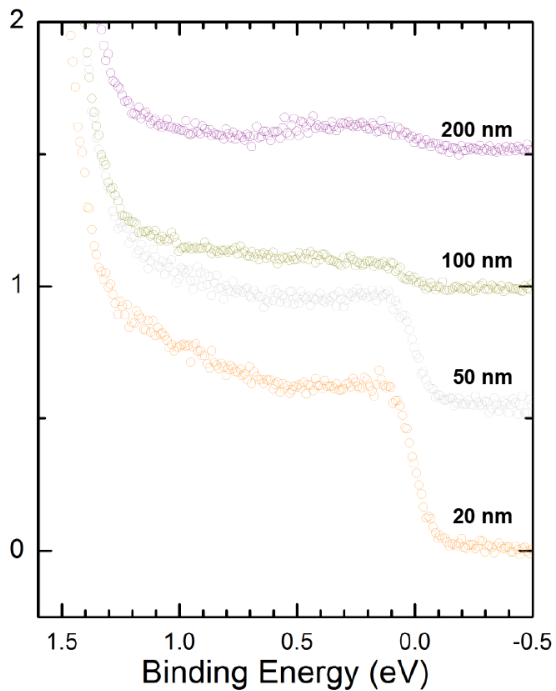

Figure S10. Expanded view of UPS emission features associated with gap/defect states below the $\mathrm{TiO}_{2}$ and PAL VB edge. Full UPS VB and SECO spectra are reported in Fig. S11. (A-C) Gap state features for nominal thicknesses up to $20 \mathrm{~nm}$ on $\mathrm{TiO}_{2}(\mathrm{~A})$, APTES-HCl (B) and APTES-KOH (C). A Fermi edge, which is associated with metallic $\mathrm{Pb}^{0}$ inclusions (Fig. S12), is observed at a BE of $0 \mathrm{eV}$. A second gap state feature with a well-defined peak around $1.2 \mathrm{eV}$, which is similar to the $\mathrm{GS}_{v_{0}}$ feature seen for the $\mathrm{AD}-\mathrm{TiO}_{2}$ sample in Fig. S8, is clearly observed for the $10 \mathrm{~nm}$ film on the bare $\mathrm{TiO}_{2}$ contact in (A). Very good overlap between the scaled $\mathrm{AD}-\mathrm{TiO}_{2} \mathrm{GS}_{V_{0}}$ feature and this second gap state near the $\mathrm{TiO}_{2}$ interface suggests reemergence of $\mathrm{GS}_{v_{0}}$ due to desorption and/or reaction of superoxide (Fig. S4), which is also correlated with positive shifts and equilibration of the $\mathrm{TiO}_{2} \mathrm{CL}$ BEs (Fig. S7). (D-F) The absence of this GS feature between 20 and $200 \mathrm{~nm}$ provides further support that this interfacial GS feature is reporting on the reemergence of the $\mathrm{GS}_{V_{0}}$ feature due to relaxation of a $\mathrm{TiO}_{2}$ interface depletion layer (see Fig. S9) induced by adsorbed superoxide species. 


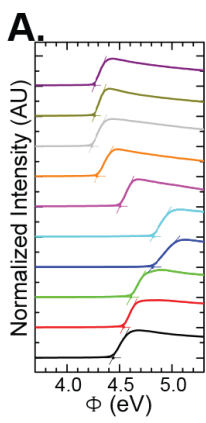

D.

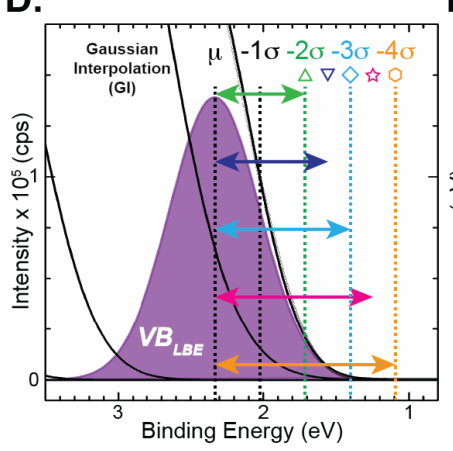

B.

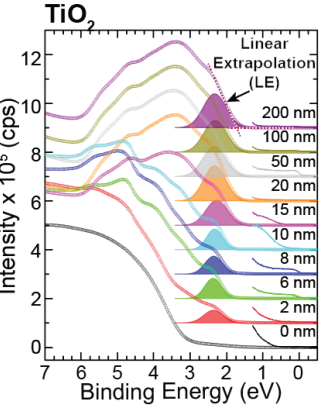

E.

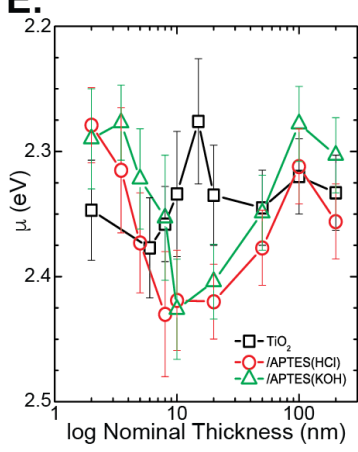

APTES-HCl

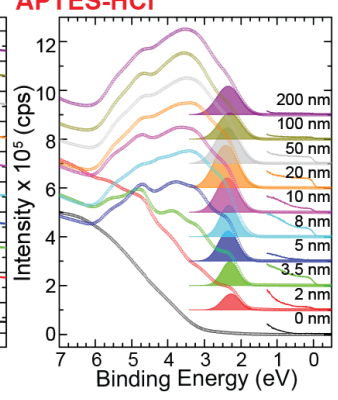

$\mathbf{F}$

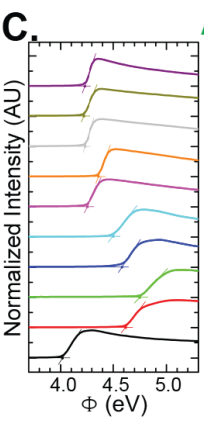

G.

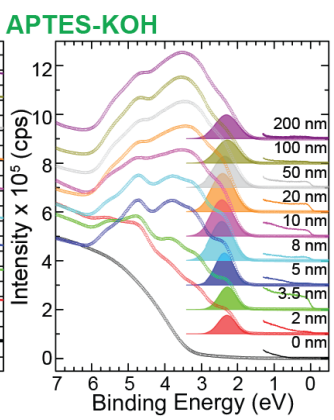

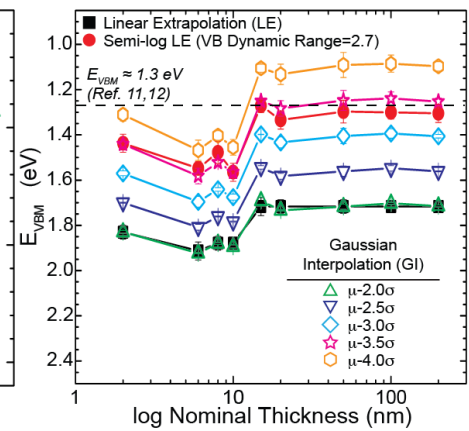
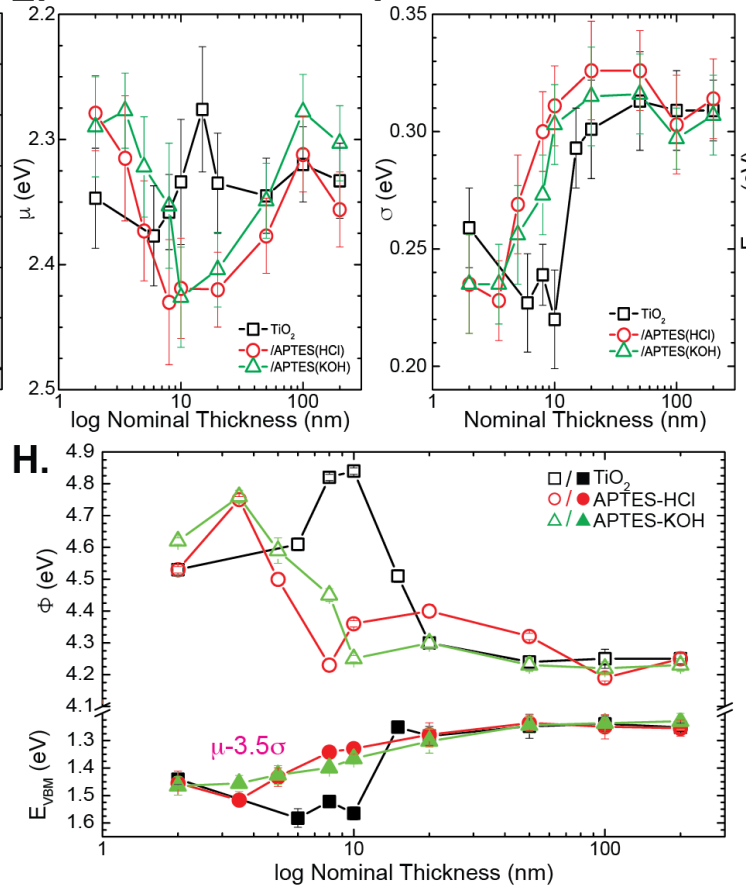

Figure S11. Monochromatic UPS (He l $\alpha$ ) analysis throughout the co-deposition of $\mathrm{MAl} / \mathrm{Pbl}_{2}$ on (A) $\mathrm{TiO}_{2}$, (B) APTES$\mathrm{HCl}$ and (C) APTES-KOH substrates. The left panel shows the low kinetic energy edge, which is referenced to the work function $(\Phi)$, and the right panel shows the VB, which is ploted on a BE scale that is referenced to $E_{F}$. All VB spectra for the MAl/Pbl 2 films are deconvoluted with a total of 5 peaks, but the low BE VB peak (VB $B_{L B E}$ ), which defines the VB onset, is only shown for each VB spectrum. The VB onset is multiplied by a factor of 50 and plotted up to $1.3 \mathrm{eV}$ to highlight low-intensity GS features, which are magnified and discussed in Fig. S10. (D) Determination of the valence band onset and, thus, valence band maximum energy ( $\mathrm{E}_{\text {Vвм}}$ ) is accomplished by using a Guassian Interpolation (GI) method, which provides a means to estimate EvBM without recourse to theory. Since PALs have an unusually low DOS at the VB edge, determination of EVBM from VB spectra is aided by comparison with theoretical calculations, ${ }^{11}$ which have yielded $\mathrm{E}_{\mathrm{VBM}}$ values of ca. $1.3 \mathrm{eV}$ for thick $\mathrm{MAPbl}_{3}$ films on $\mathrm{n}$-type contacts. In the $\mathrm{Gl}$ method, $\mathrm{VB}_{\mathrm{LBE}}$ dominates the VB edge, and $E_{V B M}$ is estimated by assuming the VB onset is defined by a specific population of $V B_{L B E}$, which is determined by subtracting a multiple of the standard deviation $(\sigma)$ from the mean $(\mu)$. (E) The thickness-dependent, average $(n=3) V_{\text {VB }}$ BE $(\mu)$. $(\mathbf{F})$ The thickness-dependent, average $(n=3)$ VB $B_{L B E}$ standard deviation $(\sigma \approx$ FWHM/2.355). (G) Comparison of the thickness-dependent $E_{\text {VвM }}$ from various estimation methods, which are traditional linear extrapolation (LE, black square), semi-log LE using a dynamic range of 2.7 (red circle) and Gaussian interpolation (GI) using a range of $\sigma$ multipliers (see graph legend). In order to yield bulk $(200 \mathrm{~nm})$ EvBM $_{\text {estimates that are similar to }}$ previous approaches for $\mathrm{MAPbl}_{3}$ films on n-type contacts that have evaluated UPS VB spectra using a combined theoretical and experimental approach, ${ }^{11-12}$ all $\mathrm{E}_{\mathrm{VBM}}$ values in this work have been estimated using a $\sigma$ multiplier of 3.5, which accounts for $99.95 \%$ of the VB ${ }_{\text {LBE }}$ population in terms of Gaussian statistics. (H) Thickness-dependent $\Phi$ and $\mathrm{E}_{\mathrm{VBM}}$. The maximum work function $\left(\Phi_{\max } \approx 4.8 \mathrm{eV}\right)$ values near the interface indicate a $\mathrm{Pbl}_{2}$-rich and MA-deficient SIL. ${ }^{12}$ The bulk work function on the three contacts (ca. $4.25 \mathrm{eV}$ ) is in close agreement with vacuum-processed MAPbl films on low work function oxide substrates. ${ }^{4,} 12$ 

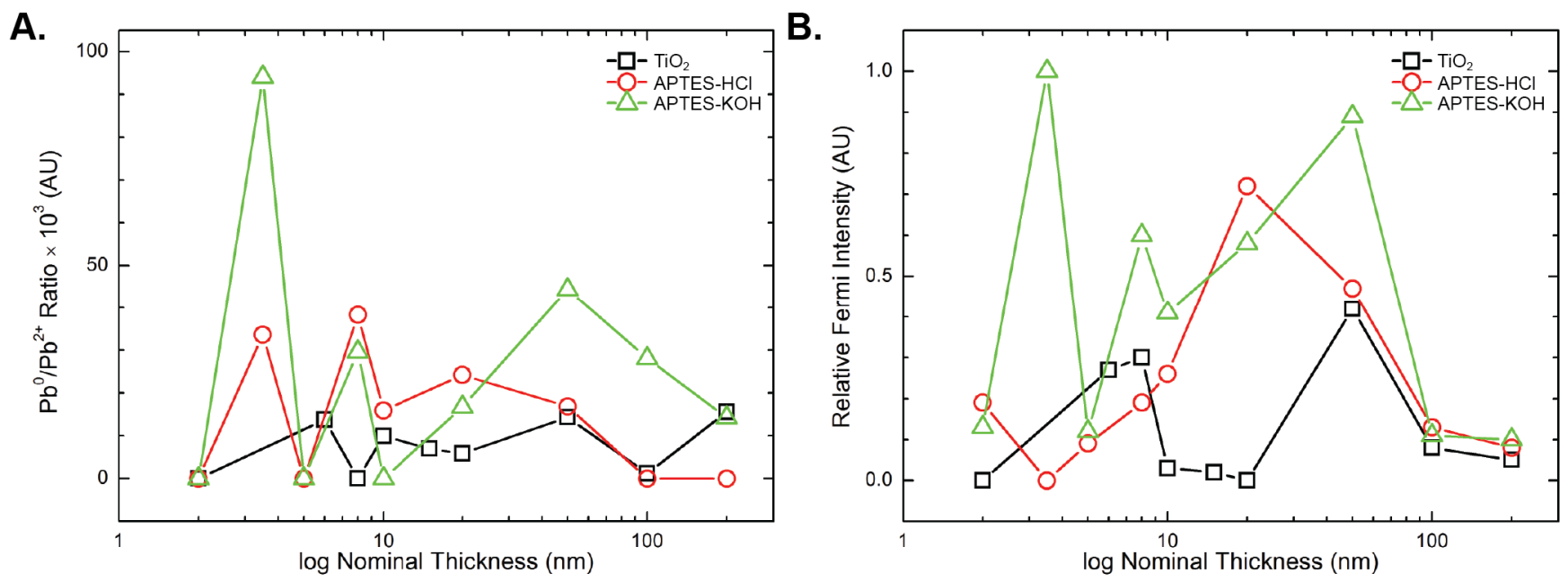

Figure S12. Evidence for the formation of metallic lead $\left(\mathrm{Pb}^{0}\right)$ during film formation. (A) $\mathrm{Pb}^{0} / \mathrm{Pb}^{2+}$ atomic ratio from the CL spectra in Fig. S5. (B) The relative intensity of the metallic Fermi feature from the UPS spectra (see Fig. S10) shows a similar trend to the $\mathrm{Pb}^{0} / \mathrm{Pb}^{2+}$ atomic ratio in $(\mathrm{A})$, indicating that the Fermi feature is due to the presence of metallic lead. In most cases, the $\mathrm{Pb} / \mathrm{Pb}^{2+}$ ratio and relative Fermi intensity is higher for the less-reactive, APTES-treated $\mathrm{TiO}_{2}$ samples, which suggests that excess, unreacted MAI results in reduction of $\mathrm{Pb}^{2+}$ species due to charge transfer between $\mathrm{I}^{-}$and $\mathrm{Pb}^{2+} .13$ 

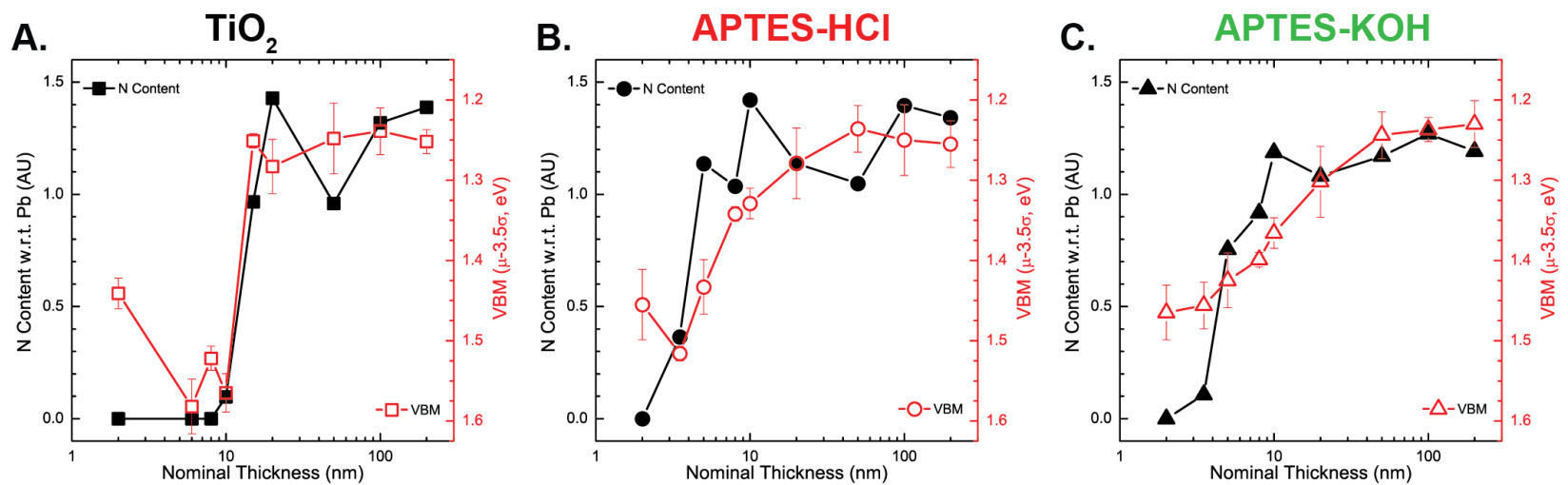

Figure S13. Correlation between the $\mathrm{N}$ content within the PAL from XPS measurements (left $y$-axis) and $E_{V B M}$ from UPS analysis (right y-axis) during film growth on (A) bare $\mathrm{TiO}_{2}$, (B) APTES-HCl and (C) APTES-KOH suggests that band bending is induced by the MA concentration gradient. ${ }^{14}$ 


\section{SI References:}

1. Williams, D. B.; Lawton, M., Drying of Organic Solvents: Quantitative Evaluation of the Efficiency of Several Desiccants. J. Org. Chem. 2010, 75, 8351-8354.

2. Shallcross, R. C.; Zheng, Y.; Saavedra, S. S.; Armstrong, N. R., Determining Band-Edge Energies and Morphology-Dependent Stability of Formamidinium Lead Perovskite Films Using Spectroelectrochemistry and Photoelectron Spectroscopy. J. Am. Chem. Soc. 2017, 139, 4866-4878.

3. Ou, K.-L.; Tadytin, D.; Xerxes Steirer, K.; Placencia, D.; Nguyen, M.; Lee, P.; Armstrong, N. R.; Steirer, K. X., Titanium Dioxide Electron-Selective Interlayers Created by Chemical Vapor Deposition for Inverted Configuration Organic Solar Cells. J. Mater. Chem. A 2013, 1, 6794-6794.

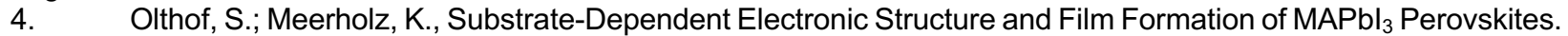
Sci. Rep. 2017, 7, 40267.

5. $\quad$ Setvin, M.; Hulva, J.; Parkinson, G. S.; Schmid, M.; Diebold, U., Electron Transfer between Anatase TiO 2 and an $\mathrm{O}_{2}$ Molecule Directly Observed by Atomic Force Microscopy. Proc. Natl. Acad. Sci. U S A 2017, 114, E2556-E2562.

6. $\quad$ Balajka, J.; Hines, M. A.; DeBenedetti, W. J. I.; Komora, M.; Pavelec, J.; Schmid, M.; Diebold, U., High-Affinity Adsorption Leads to Molecularly Ordered Interfaces on $\mathrm{TiO}_{2}$ in Air and Solution. Science 2018, 361, 786-789.

7. Krishnan, P.; Liu, M.; Itty, P. A.; Liu, Z.; Rheinheimer, V.; Zhang, M. H.; Monteiro, P. J.; Yu, L. E., Characterization of Photocatalytic $\mathrm{TiO}_{2}$ Powder under Varied Environments Using near Ambient Pressure X-Ray Photoelectron Spectroscopy. Sci. Rep. 2017, 7, 43298.

8. Kashiwaya, S.; Morasch, J.; Streibel, V.; Toupance, T.; Jaegermann, W.; Klein, A., The Work Function of TiO 2. Surfaces 2018, 1, 73-89.

9. Juarez-Perez, E. J.; Hawash, Z.; Raga, S. R.; Ono, L. K.; Qi, Y., Thermal Degradation of $\mathrm{CH}_{3} \mathrm{NH}_{3} \mathrm{Pbl} 3$ Perovskite into $\mathrm{NH}_{3}$ and $\mathrm{CH}_{3}$ l Gases Observed by Coupled Thermogravimetry-Mass Spectrometry Analysis. Energy \& Environ. Sci. 2016, 9, 3406-3410.

10. Nenon, D. P.; Christians, J. A.; Wheeler, L. M.; Blackburn, J. L.; Sanehira, E. M.; Dou, B.; Olsen, M. L.; Zhu, K.; Berry, J. J.; Luther, J. M., Structural and Chemical Evolution of Methylammonium Lead Halide Perovskites During Thermal Processing from Solution. Energy \& Environ. Sci. 2016, 9, 2072-2082.

11. Endres, J., et al., Valence and Conduction Band Densities of States of Metal Halide Perovskites: A Combined Experimental-Theoretical Study. J. Phys. Chem. Lett. 2016, 7, 2722-2729.

12. Zhou, X.; Li, X.; Liu, Y.; Huang, F.; Zhong, D., Interface Electronic Properties of Co-Evaporated MAPbl 3 on $\mathrm{ZnO}(0001)$ : In Situ X-Ray Photoelectron Spectroscopy and Ultraviolet Photoelectron Spectroscopy Study. Appl. Phys. Lett. 2016, 108, 121601.

13. Lindblad, R.; Bi, D.; Park, B. W.; Oscarsson, J.; Gorgoi, M.; Siegbahn, H.; Odelius, M.; Johansson, E. M.; Rensmo, H., Electronic Structure of $\mathrm{TiO}_{2} / \mathrm{CH}_{3} \mathrm{NH}_{3} \mathrm{Pbl}_{3}$ Perovskite Solar Cell Interfaces. J. Phys. Chem. Lett. 2014, 5, 648-653.

14. Emara, J.; Schnier, T.; Pourdavoud, N.; Riedl, T.; Meerholz, K.; Olthof, S., Impact of Film Stoichiometry on the Ionization Energy and Electronic Structure of $\mathrm{CH}_{3} \mathrm{NH}_{3} \mathrm{Pbl}_{3}$ Perovskites. Adv. Mater. 2016, 28, 553-559. 